Estudios Constitucionales, Año 16, № 2, 2018, pp. 403-448

ISSN 07180195

Centro de Estudios Constitucionales de Chile Universidad de Talca

"La búsqueda de la democracia en Hong Kong: ¿̨un caso de Realpolitik o un conflicto de Doctrina Constitucional?"

Peter C.H. Cha - Viviana Ponce de León Solís

\title{
LA BÚSQUEDA DE LA DEMOCRACIA EN HONG KONG: ¿UN CASO DE REALPOLITIK O UN CONFLICTO DE DOCTRINA CONSTITUCIONAL?*
}

\section{The Pursuit of Democracy in Hong Kong: A Case of Realpolitik or a Conflict of Constitutional Jurisprudence?}

\author{
Peter C.H. ChA ${ }^{* *}$ \\ City University of Hong Kong \\ pchchan@cityu.edu.hk \\ Viviana Ponce de León Solís** \\ Universidad Católica del Norte \\ poncedeleonviviana@gmail.com
}

RESUMEN: La literatura existente contribuye al estancamiento en la búsqueda del sufragio universal en Hong Kong y a las disputas políticas entre Beijing y los partidos de oposición en Hong Kong. Si bien la Realpolitik ha desempeñado un rol crucial modelando la reforma constitucional de Hong Kong, este artículo plantea que el choque entre tradiciones constitucionales ha sido igualmente importante. La perspectiva constitucional china abraza el principio fundamental de delegación del poder. Los poderes delegados deben ser ejercidos por Hong Kong sobre la base de que Beijing retiene su poder soberano. La postura liberal, que enfatiza la supremacía de la ley, afirma que Beijing está igualmente sometido por la Ley Básica. Este artículo sostiene que la falta de consenso tanto en la definición de "sufragio universal" como en los diseños institucionales concretos para el sufragio universal son los principales obstáculos para el desarrollo de la democracia en Hong Kong. Estos obstáculos no pueden ser superados a menos que ambos lados puedan acordar una interfaz constitucional mutuamente aceptable.

ABSTRACT: Existing literature contributes the deadlock in Hong Kong's quest for universal suffrage and to the political gridlock between Beijing and the opposition parties in Hong Kong. While Realpolitik played a crucial role in shaping Hong Kong's constitutional reform, this article argues that the clash of constitutional traditions had been equally important. The Chinese constitutional perspective embraces the fundamental principle of delegation of power. The delegated powers must be exercised by

\footnotetext{
* Trabajo recibido el 1 de marzo de 2018 y aprobado el 10 de octubre de 2018.

** Ph.D., Maastricht University. Profesor Asistente, Escuela de Derecho, City University of Hong Kong. Abogado, Región Administrativa Especial de Hong Kong (no practicante). Abogado, Inglaterra y Gales (no practicante).

${ }^{* * *}$ Doctora en Derecho, Pontificia Universidad Católica de Valparaíso. Profesora de Derecho Constitucional, Universidad Católica del Norte.
} 
Hong Kong on the basis that Beijing retains plenary powers. The liberal view, which emphasizes the supremacy of the law, argues that Beijing is equally bound by the Basic Law. This article argues that the lack of consensus on both the definition of "universal suffrage" and concrete institutional designs for universal suffrage are the key obstacles to the development of democracy in Hong Kong. These obstacles cannot be overcome unless both sides can agree to a mutually acceptable constitutional interface.

Palabras Clave: Democracia, sufragio universal, reforma constitucional, Hong Kong, Beijing, China.

KEY WORDS: Democracy, universal suffrage, constitutional reform, Hong Kong, Beijing, China.

\section{INTRODUCCIÓN}

La búsqueda de la democracia ha sido una lucha constante en Hong Kong, actual Región Administrativa Especial de la República Popular de China y excolonia británica. Gobernado según el principio "un país, dos sistemas", Hong Kong cuenta con una miniconstitución propia -la Ley Básica-, ejerce un "elevado grado de autonomía, y goza de poder ejecutivo, legislativo y judicial independiente" (artículo 20 de la Ley Básica). De este modo, es posible la articulación del sistema económico capitalista de Hong Kong con el sistema político comunista de la China continental. Sin perjuicio de lo anterior, se reserva a la competencia del Gobierno Central el nombramiento del Jefe Ejecutivo y de los principales oficiales de las autoridades del Ejecutivo de Hong Kong. Este Jefe Ejecutivo es elegido "por sufragio universal, previa nominación por un comité nominador ampliamente representativo" (artículo 15 de la Ley Básica). Por su parte, para la selección de los miembros del Consejo Legislativo de Hong Kong se han configurado circunscripciones geográficas y funcionales (Anexo II de la Ley Básica), que consideran tanto el voto individual como el voto corporativo y que ameritan cuestionamientos adicionales desde la perspectiva del principio democrático.

Todo ello parecía cambiar el año 2004, cuando el Gobierno Central dio muestras de su voluntad en orden a la celebración de elecciones libres y directas del Jefe Ejecutivo y del Consejo Legislativo, para los años 2017 y 2020, respectivamente. Para que tal reforma pudiera ser implementada exitosamente, tres requisitos copulativos debían cumplirse. En primer lugar, el Comité Permanente de la Asamblea Popular Nacional -órgano nacional facultado para interpretar la constitución y las leyes de la República Popular China, así como la Ley Básica de Hong Kong- debía emitir una declaración respecto de la necesidad de reformar el método para elegir al Jefe Ejecutivo. En segundo lugar, la reforma debía ser aprobada por el voto favorable de los dos tercios de los miembros del Consejo Legislativo. Y, en tercer lugar, se requería la aprobación del Jefe Ejecutivo y del 
Comité Permanente. Si cualquiera de estos requisitos fallaba, la reforma fracasaría y no podría implementarse.

La promesa de sufragio universal en Hong Kong estuvo aún más cerca de concretarse con una declaración emitida al efecto por el Comité Permanente el año 2007. Mas, si bien con ella era posible iniciar el proceso de reforma, ésta se condicionaba al cumplimiento de una serie de requisitos sumamente restrictivos que no se condecían con estándares democráticos occidentales. Entre tales condiciones se encontraba que el Jefe Ejecutivo fuera seleccionado por un comité nominador, bajo el entendido de tratarse de la única fórmula ajustada a la Ley Básica de Hong Kong. Para los partidos de oposición, por el contrario, las restricciones únicamente tenían por objeto asegurar la lealtad de los candidatos nominados al Gobierno Central. Además, por si lo anterior no fuese suficiente, tampoco se alcanzó el cuórum de los dos tercios del voto favorable de los miembros del Consejo Legislativo necesario para la aprobación de la reforma.

En este contexto cientos de miles de personas se movilizaron en la "Revolución de los Paraguas", para reclamar la instauración del sufragio universal en Hong Kong. La prensa y la literatura especializada interpretaron la situación como un enfrentamiento entre los partidos leales a Beijing y los partidos de oposición. Con todo, no resulta claro si se trata de un problema de ausencia de voluntad política, de falta de comprensión de los valores conservadores y liberales involucrados, de simple temor a la reacción de China o de una combinación de todas las anteriores. Así las cosas, la idea central de la presente investigación es que la literatura existente contribuye al estancamiento en la búsqueda del sufragio universal en Hong Kong y al debate político entre Beijing y los partidos de oposición en Hong Kong. Ciertamente, no puede desconocerse que consideraciones pragmáticas o de Realpolitik han tenido un rol decisivo en el desarrollo del proyecto de reforma electoral en Hong Kong. Sin embargo, tampoco puede desconocerse que el choque entre las tradiciones jurídicas de Hong Kong y China también ha tenido un rol significativo.

Para el desarrollo de esta idea, el artículo se ha estructurado del siguiente modo. Para comenzar, tras una breve referencia al sistema electoral de Hong Kong, se analiza el proyecto de su reforma y las razones de su fracaso. Luego, se expone cómo la diferencia de tradiciones jurídicas entre Hong Kong (common law) y entre China (derecho continental europeo) incide en el debate en torno a los alcances de la reforma al sistema electoral. En este orden de ideas, se realiza un análisis comparativo de las doctrinas de Hong Kong y de China en cuanto a dos aspectos centrales: las obligaciones que la Ley Básica impone al poder 
Central y el alcance de la internacionalización del derecho constitucional en Hong Kong. Por último, se discute el rol que podrían tener en el éxito de una eventual futura reforma al sistema electoral algunas de las instituciones jurídicas ya existentes o en uso en Hong Kong. Más concretamente, se analiza cómo las circunscripciones funcionales, las convenciones constitucionales y el Comité para la Ley Básica podrían contribuir a suavizar el conflicto.

\section{El fracaso de la democratización en Hong Kong}

\subsection{Generalidades en torno al sistema electoral de Hong Kong}

Para la comprensión del sistema electoral de Hong Kong y del objeto de la presente investigación, es necesario pasar revista al método de elección de tres órganos: (i) el Jefe Ejecutivo de Hong Kong, (ii) el Comité Electoral y (iii) el Consejo Legislativo. A la luz de este análisis será posible apreciar el modo en que el gobierno de Hong Kong se relaciona con el Gobierno Central de la República Popular de China, particularmente en términos del verdadero grado de autonomía del primero y de la efectiva vigencia de la fórmula "un gobierno, dos sistemas". De igual manera, permitirá entender las críticas que se dirigen contra el sistema y los argumentos en que se suele fundar la necesidad de su reforma.

El Jefe Ejecutivo de Hong Kong es el Presidente del Consejo Ejecutivo de Hong Kong -órgano asesor análogo a un gabinete o consejo de ministros- y del Gobierno de la Región Administrativa Especial de Hong Kong. Él es el jefe de Estado y de Gobierno de la Región Administrativa Especial de Hong Kong y representante de la misma ante el Gobierno Central Popular. Cabe destacar además que él es responsable ante el Gobierno Central (artículo 43 de la Ley Básica), cuya aprobación es necesaria para el nombramiento y remoción de los oficiales principales (artículo 48.5 de la Ley Básica). Asimismo, le corresponde emitir la decisión final acerca del impeachment del Jefe Ejecutivo (artículo 48.9 de la Ley Básica). En este sentido puede afirmarse que el Jefe Ejecutivo se encuentra sujeto a una fuerte dependencia respecto del Gobierno Central.

El Jefe Ejecutivo es elegido por un cuerpo nominador, denominado Comité Electoral. Así, de acuerdo con el punto 2 del Anexo I de la Ley Básica de la Región Administrativa Especial de Hong Kong, "[l] os candidatos para el cargo de Jefe Ejecutivo pueden ser nominados conjuntamente por no menos de 150 miembros del Comité Electoral. Cada miembro puede nominar sólo un candidato". De acuerdo con la Ordenanza para la Elección del Jefe Ejecutivo (OEJE), habiendo dos o más 
candidatos válidamente nominados, se procede a la elección. El candidato que obtenga más de 600 votos válidamente emitidos en la primera votación será elegido. Si ninguno de los candidatos obtiene más de 600 votos, se procederá a una nueva elección entre los dos candidatos que hayan obtenido las más altas mayorías relativas (Parte 5, Sección 27 de la OEJE). El candidato que obtenga más de 600 votos será proclamado Jefe Ejecutivo por el Gobierno Popular Central.

Por su parte, el Comité Electoral está compuesto por un total de 1200 miembros provenientes de cuatro sectores, de 300 integrantes cada uno (Anexo I de la Ley Básica). Los cuatro sectores son: (i) Industrial, Comercial y Financiero; (ii) Profesionales; (iii) Representantes de los Trabajadores, Servicios Sociales, Religiosos y Otros, y (iv), por último, Miembros del Consejo Legislativo, Representantes del Heung Yee Kuk ${ }^{1}$, Diputados de Hong Kong ante el Congreso Popular Nacional y Representantes del Comité Nacional de la Conferencia Consultiva Política del Pueblo Chino (Anexo I de la Ley Básica). Cada uno de esos cuatro sectores, a su vez, está formado por un número determinado de un total de 38 subsectores. Cada subsector, por su parte, tiene asignado un número determinado de representantes en el Comité ${ }^{2}$, que no necesariamente es proporcional al número de votantes que lo conforma.

El procedimiento para la elección de los miembros del Comité Electoral es regulado detalladamente en las Partes 2 y 3 de la OEJE. De acuerdo con dicha regulación, de los 1200 miembros totales, 1034 son elegidos por 35 subsectores (Tablas 1, 2, 3 y 4 de la Parte 2 de la OEJE). En esta elección participan

\footnotetext{
1 Heung Yee Kuk es un órgano consultivo que representa los intereses del Gobierno en los Nuevos Territorios (una de las tres principales regiones de Hong Kong, junto con la isla y la península de Hong Kong).

2 El primer sector -Industrial, Comercial y Financiero- comprende 17 subsectores con 18 representantes en el Comité Electoral, excepto en los que se indica entre corchetes lo contrario: Catering [17]; Comercio (primero); Comercio (segundo); Federación de Empleadores [16]; Finanzas; Servicios Financieros; Asociación de Empleados [16]; Hostelería [17]; Importación y Exportación; Industria (primero); Industria (segundo); Seguros; Inmobiliario y Construcción; Textil; Turismo; Transporte; Venta Mayorista y Minorista. El segundo sector -de los Profesionales- comprende 10 subsectores con 30 representantes en el Comité Electoral cada uno: Contabilidad; Arquitectura, Supervisión y Planificación; Medicina China; Educación; Ingeniería; Servicios Sanitarios; Educación Superior; Tecnología de la Información; Jurídico: y Médico. El tercer sector -de los profesionales- comprende los siguientes subsectores con 30 representantes en el Comité Electoral cada uno: Finalmente, el cuarto sector -de los profesionales- comprende cinco subsectores con 60 representantes en el Comité Electoral cada uno: Agricultura y Pesca; Laboral; Religioso; Servicios Sociales, y Deportes, Artes Escénicas, Cultura y Editorial. está integrado únicamente por miembros ex officio, cuyo número se indica entre corchetes: Diputados de Hong Kong ante el Congreso Popular Nacional [36]; Representantes del Comité Nacional de la Conferencia Consultiva Política del Pueblo Chino [51]; Miembros del Consejo Legislativo [70], Representantes del Heung Yee Kuk [26]; Miembros electos de los Consejos de Distrito de Hong Kong (isla) y Kowloon [57], y Miembros Electos de los Consejos de Distrito de Nuevos Territorios [60].
} 
aproximadamente 250.000 votantes individuales y corporativos, considerando el número total de votantes registrados de los 35 subsectores en las elecciones de $2011^{3}$ y $2016^{4}$. 60 miembros son designados directamente por el subsector religioso, de modo que no hay elecciones (Parte 3.7 de la OEJE). Finalmente, 106 son miembros ex officio -invisten la calidad de miembros del Comité en razón de ser diputados del Congreso Nacional Popular y miembros del Consejo Legislativo de Hong Kong-, de modo que en estos dos subsectores tampoco hay elecciones (Partes 2.2.(7).(c).(ii) y 2.2.(8).(b) de la OEJE).

Finalmente, corresponde hacer una referencia al Consejo Legislativo. Éste es el órgano legislativo unicameral de Hong Kong, integrado por 70 miembros. La mitad de ellos se elige directamente por sufragio universal a través de cinco circunscripciones geográficas, que actualmente son Hong Kong, Isla; Kowloon Oeste; Kowloon Este; Nuevos Territorios Oeste, y Nuevos Territorios Este. La determinación de las circunscripciones geográficas corresponde al Jefe Ejecutivo, tomando en cuenta las recomendaciones de la Comisión de Asuntos Electorales, según lo dispuesto en la Sección 18 de la Ordenanza sobre el Consejo Legislativo (OCL). En la elección se utiliza un sistema de representación proporcional en el que la distribución de escaños se calcula mediante el método Hare. En ella pueden votar todos los ciudadanos mayores de edad con residencia permanente en Hong Kong que no estén afectos a una causal de exclusión legal.

La otra mitad de los miembros del Consejo Legislativo es elegida a través de circunscripciones funcionales, que representan 29 sectores de la comunidad (Sección 20 de la OCL) $)^{5}$. A cada uno de ellos le corresponde sólo un escaño, excepto a los sectores Sindical y Consejos de Distrito (dos), a los que les corresponden 3 y 5 , respectivamente. La peculiaridad que presenta esta clase de circunscripciones es que algunas de ellas están compuestas casi íntegramente por votantes corporativos (por ejemplo, en los sectores Seguros; Inmobiliaria y Construcción; Finanzas, y Servicios Financieros). De este modo, sólo tienen derecho a voto los representantes de personas

3 Election Committee Subsector Elections Breakdown of Voters for Election Committee Subsectors (2011).

4 Election Committee Subsector Elections Breakdown of Voters for Election Committee Subsectors (2016).

5 Los 29 sectores se listan a continuación: Heung Yee Kuk; Agricultura y Pesca; Seguros; Transporte; Educación; Jurídico; Contabilidad; Médico; Servicios de Salud; Ingeniería, Arquitectura, Supervisión y Planficación; Sindical; Servicios Sociales; Inmobiliaria y Construcción; Turismo; Comercio (primero); Comercio (segundo); Industrial (primero); Industrial (segundo); Finanzas; Servicios Financieros; Deporte, Arte y Cultura; Importación y Exportación; Textil; Comercio Mayorista y Minorista; Tecnología de la Información; Catering; Consejos de Distrito (uno); Consejos de Distritos (dos). 
jurídicas acreditadas o autorizadas del respectivo subsector. En otras, en cambio, el voto es individual (por ejemplo, en los sectores Educación; Médico; e Ingeniería).

El sistema admite críticas desde distintos frentes.

Respecto del método de elección del Jefe Ejecutivo, uno de las principales observaciones se refiere a la composición del Comité Electoral, en cuanto a su integración restringida a grupos privilegiados de la sociedad y a la representación desproporcionada de los intereses del sector industrial, comercial y financiero ${ }^{6}$. Esto último se apreciaría especialmente en extensión de la figura del voto corporativo en diversos subsectores. Asimismo, se reprocha la intervención del Gobierno Central en el nombramiento del Jefe Ejecutivo, presumiblemente a fin de garantizar la lealtad de este último a Beijing. El reproche se fundaría en el potencial compromiso que ello supondría al "elevado grado de autonomía" de Hong Kong y a la viabilidad de la fórmula "dos países, un sistema"7.

Por lo que concierne a la elección del Consejo Legislativo, los reproches apuntan a la naturaleza inherentemente antidemocrática e injusta de las circunscripciones funcionales, toda vez que su configuración se traduce en una ruptura del principio de igualdad del voto ${ }^{8}$. Así, se objeta que esta clase de circunscripciones da un poder desproporcionado a ciertas minorías selectas, lo cual resulta particularmente evidente si se tiene presente que en algunas de ellas concurren tanto votantes individuales como corporativos, con distintos grados de atomización, en este último caso ${ }^{9}$. Por otro lado, el sistema sólo da derecho a voto a un pequeño porcentaje de la población, basado en su pertenencia o registro en determinados cuerpos o sectores sociales, económicos, industriales, comerciales, políticos o profesionales ${ }^{10}$.

\subsection{El proyecto para la instauración del sufragio universal en Hong Kong}

Como se puede apreciar a partir de todo lo hasta ahora expuesto, la instauración del sufragio universal en Hong Kong suponía un proyecto complejo. En

\footnotetext{
6 Young (2014), p. 692; YeUng (2002), pp. 244 y ss.

7 YeUnG (2002), p. 245.

8 Una crítica general a las circunscripciones funcionales puede verse en YounG; LaW (2006), pp. 59-109; Young (2006), pp. 111-142.

9 Chu; So (2013), p. 224; Li; Kat (2013), pp. 148 y ss.

10 Young; Law (2006), p. 59.
} 
efecto, este proyecto no sólo involucraba el ejercicio de una opción política por parte del pueblo de Hong Kong, sino también el ejercicio de poderes soberanos por parte de Beijing. Sus orígenes se remontan al cambio de milenio, con la Interpretación del Comité Permanente de la Asamblea Popular Nacional de 200411. Mediante este instrumento se introdujo el denominado "Procedimiento de Cinco Pasos para la reforma de los métodos electorales para la selección del Jefe Ejecutivo, y de la formación del Consejo Legislativo".

En 2007, el Comité Permanente emitió una decisión estableciendo un cronograma oficial para la implementación del sufragio universal en Hong Kong. Según este cronograma el Jefe Ejecutivo y el Consejo Legislativo "podrían" ser elegidos sobre la base del sufragio universal para los años 2017 y 2020, respectivamente ${ }^{12}$. El énfasis está en la expresión "podrían", dado que el éxito de la implementación del sufragio universal estaba sujeto a una serie de prerrequisitos. Conforme al Procedimiento de Cinco Pasos, cada uno de los tres actores constitucionales claves -Beijing, el Jefe Ejecutivo de turno y el Consejo Legislativo del momento- debía pronunciarse a favor de la implementación de la propuesta de sufragio universal en la forma que se le ha presentado. Si cualquiera de estos tres actores clave rechazaba la propuesta, el sufragio universal no sería posible.

Lo que sigue es un breve punteo de los pasos constitucionales adoptados en la reforma de 2015 -que finalmente no fue aprobada por el Consejo Legislativo-, que buscaba instaurar el sufragio universal en la elección del Jefe Ejecutivo de 2017, en concordancia con la decisión del Comité Permanente de 2007. Los pasos fueron desarrollados de acuerdo con el Procedimiento de Cinco Pasos ${ }^{13}$.

11 The Interpretation by the Standing. Committee of the National People's Congress of Article 7 of Annex I and Article III of Annex II to the Basic Law of the Hong Kong Special. Administrative Region of the People's Republic of China. Véase, en particular, el párrafo 3 de la Interpretación.

12 Decision of the Standing Committee of the National People's Congress on Issues Relating to the Methods for Selecting the Chief Executive of the Hong Kong Special Administrative Region and for Forming the Legislative Council of the Hong Kong Special Administrative Region in the Year 2012 and on Issues Relating to Universal Suffrage.

13 Previo al inicio del Procedimiento de Cinco Pasos, el gobierno de Hong Kong condujo la primera ronda de consulta pública en diciembre de 2013. La consulta culminó en un reporte de consulta publicado en julio de 2014, bajo el título de "Report on the Public Consultation on the Methods for Selecting the Chief Executive in 2017 and for Forming the Legislative Council in 2016". 
a) Paso 1: El 15 de julio de 2014, tras una consulta de cinco meses, el Jefe Ejecutivo presentó un reporte de reforma electoral a Beijing, estableciendo lo que el gobierno consideraba un paquete de reformas necesarias para la implementación del sufragio universal en la selección del Jefe Ejecutivo en 2017.

b) Paso 2: El 31 de agosto de 201414, el Comité Permanente estableció que a partir del 2017 la selección del Jefe Ejecutivo podría ser implementada mediante el método de sufragio universal, pero impuso al efecto una serie de condiciones restrictivas que dificultaban la reforma:

(i) Debía formarse un comité nominador ampliamente representativo. Las disposiciones relativas al número de miembros, composición y método de formación del comité nominador debían dictarse en concordancia con el número de miembros, composición y método de formación del Comité de Electoral entonces vigente.

(ii) El comité nominador debía nominar a dos o tres candidatos para el cargo de Jefe Ejecutivo conforme a procedimientos democráticos. Cada candidato debía contar con el patrocinio de más de la mitad de todos los miembros del Comité Nominador.

(iii) Todos los electores de Hong Kong tendrían derecho a votar en la elección del Jefe Ejecutivo y elegir a uno de los candidatos para ese cargo, de acuerdo con la ley ${ }^{15}$.

(iv) Tras su elección por sufragio universal, el Jefe Ejecutivo electo debía ser investido por el Gobierno Popular Central.

c) Paso 3: En abril de 2015, el gobierno de Hong Kong publicó el "Método para la selección del Jefe Ejecutivo por sufragio universal: Reporte de consulta y propuestas"16. En línea con la Decisión del 31 de agosto, en este documento se sentaban las bases para introducir al Consejo Legislativo una moción sobre enmiendas al método electoral.

La Propuesta de 2015 comprendía tres elementos fundamentales:

14 Decision of the Standing Committee of the National People's Congress on Issues Relating to the Selection of the Chief Executive of the Hong Kong Special Administrative Region by Universal Suffrage and on the Method for Forming the Legislative Council of the Hong Kong Special Administrative Region in the Year 2016.

15 La elección general es una elección directa de una-persona-un-voto abierta a todos los votantes registrados en Hong Kong (hasta 2015, habían 3.693.942 votantes registrados en Hong Kong; la población total de Hong Kong es de alrededor de 7,3 millones al término de 2015).

16 Method for Selecting the Chief Executive by Universal Suffrage: Consultation Report and Proposals. 
(i) Primero, en relación con la composición del Comité Nominador, el gobierno de Hong Kong propuso que éste siguiera la composición del Comité Electoral ${ }^{17}$.

(ii) Segundo, en relación con el proceso de nominación, el gobierno de Hong Kong sugirió que hubiera dos etapas: la etapa de "recomendación de miembro" y la etapa de "comité de nominación".

Para la primera etapa, cualquier candidato que buscara la nominación debía primero obtener la recomendación de alguno de los 120 miembros del Comité Nominador. Cada miembro podría recomendar sólo un candidato. El candidato que superara esta etapa pasaría a la siguiente ${ }^{18}$.

Por lo que respecta a la segunda etapa, el gobierno de Hong Kong sugirió que el Comité Nominador debía nominar dos o tres candidatos a Jefe Ejecutivo, mediante votación secreta. Cada miembro del Comité Nominador debería patrocinar al menos dos personas que buscaran la nominación. Los postulantes que obtuvieran el patrocinio de más de la mitad de todos los miembros del Comité Nominador y el mayor número de patrocinios de los miembros se convertirían en los candidatos ${ }^{19}$.

(iii) Tercero, en relación con el diseño de la elección general, el gobierno de Hong Kong sugirió que todos sus votantes elegibles eligieran al Jefe Ejecutivo entre los dos o tres candidatos nominados por el Comité Nominador, en virtud de un sistema electoral de sufragio directo ${ }^{20}$.

El 18 junio de 2015, la "Moción Concerniente a la Enmienda del Método de Selección del Jefe Ejecutivo de la Región Administrativa Especial de Hong Kong" 21 del gobierno fue rechazada por el Consejo Legislativo. Ello fue un golpe decisivo a la democratización de Hong Kong. Ambos extremos del espectro político parecían reacios -o al menos políticamente incapaces- de hacer las concesiones necesarias para que Hong Kong avanzara en su camino

\footnotetext{
17 Ibíd., párr. 3.10.

18 Una persona que busque nominación debería obtener no más de 240 y no menos de 120 recomendaciones. De acuerdo con estos límites máximos y mínimos como umbral de "entrada", el sistema podría admitir al menos cinco y como mucho diez vacantes para personas que busquen nominación. Ibíd., párr. 3.21.

19 Ibíd., párr. 3.21.

20 Ibíd., párr. 3.29.

21 Motion concerning the Amendment to the Method for the Selection of the Chief Executive of the Hong Kong Special Administrative Region.
} 
hacia la democracia. La política constitucional subyacente al rechazo al paquete de reforma electoral del gobierno no es difícil de entender. A modo de antecedente, el escenario político en Hong Kong consiste esencialmente en dos bloques de poder: la Coalición de Oposición o "Pan-democrática", que es una agrupación liberal de partidos de oposición, y la coalición "Pro-régimen", que es un grupo de partidos políticos conservadores alineados con el gobierno de Hong Kong y leales a Beijing 22 . La reforma constitucional en Hong Kong sólo puede ser exitosa si los dos bloques de poder pueden hacer concesiones, dado que ninguno de ellos tiene una supramayoría (dos tercios del voto) en el Consejo Legislativo.

\subsection{El problema abordado en la presente investigación}

Dado que el término "sufragio universal" adolece de ambigüedad y carece de una definición clara, surge la pregunta: ¿qué clase de instituciones encarnaría de mejor modo el principio de sufragio universal en Hong Kong? Desde una perspectiva político-constitucional, los integrantes más moderados de la Coalición de Oposición exigieron una elección en 2017 sin restricciones irrazonables al derecho del pueblo de Hong Kong a votar. Esto, sin duda, no descartaba la posibilidad de tener un comité de nominación, en la medida que el cuerpo de nominación fuera ampliamente representativo. Posiciones más radicales exigían un proceso de nominación civil, bien que operara en paralelo al comité de nominación o que operara sin un cuerpo de nominación. Estas posiciones revelan que la Coalición de Oposición fue incapaz de apreciar las inquietudes de Realpolitik en orden a que Hong Kong se podría convertir en una base antiBeijing, si el Gobierno Popular Central no asumía un rol activo en la selección de la autoridad más alta en Hong Kong ${ }^{23}$. Si bien es una posición asentada que el Gobierno Central tiene el poder sustantivo para nombrar o rechazar al Jefe Ejecutivo electo, el ejercicio de este poder supone rechazar al candidato ganador

\footnotetext{
22 Para efectos de este artículo, el término "conservador" es usado para describir la posición pro-Beijing y "liberal" es usado para describir la posición generalmente asumida por la Coalición de Oposición (o coalición "pan-democrática" en Hong Kong).

23 La perspectiva liberal explica que la falta de disposición de Beijing para acelerar el proceso de democratización en Hong Kong se debe a una enraizada sospecha hacia los demócratas liberales y a una preocupación por una captura de la oposición sobre el Consejo Legislativo si el sufragio universal fuera implementado muy rápidamente. DAVIS (2007), p. 81.
} 
resultante de una-persona-un-voto, lo cual casi ciertamente desencadenaría una crisis constitucional de proporciones inimaginables.

Demasiado se ha dicho, tanto en los medios como en la academia, acerca las políticas constitucionales que contribuyeron al fracaso de la democratización de Hong Kong. Si bien la Realpolitik representó un rol importante en la configuración de la reforma constitucional de Hong Kong, aquí se sostiene que la colisión de tradiciones constitucionales ha sido igualmente importante. La desconfianza y controversia que ha acompañado cada crisis desde la devolución no ha sido puramente el producto de la competencia por recursos políticos e influencia. Las diferencias fundamentales en ideología política, teoría constitucional, valores jurídicos y la comprensión de aquello que es necesario para implementar exitosamente la fórmula "un país, dos sistemas", forma el locus en que la política partidista opera y la tensión entre Beijing y Hong Kong se acumula. La colisión de tradiciones constitucionales se manifiesta desde el debate constitucional hasta la confrontación política abierta, cuando el derecho constitucional se intersecta con asuntos altamente politizados. Este artículo se ocupa de uno de tales asuntos, a saber, la reforma electoral de Hong Kong. Se afirma que la falta de consenso tanto en la definición del sufragio universal y en el concreto diseño para la implementación del sufragio universal son obstáculos igualmente fundamentales para el desarrollo de la democracia en Hong Kong.

\section{La COLISIÓN DE TRADICIONES CONSTITUCIONALES - PERSPECTIVAS DEL COMMON LAW Y DEL DERECHO CHINO SOBRE LA LEY BÁSICA}

Las intersecciones del common law y las normas del derecho chino forman el tejido mismo del régimen constitucional de la Ley Básica y siguen siendo fuente de tensión continua. En estas intersecciones, el conflicto de valores jurídicos así como de intereses políticos revelan la complejidad de un orden constitucional dualista, en el que la discreción del soberano debe coexistir en un equilibrio sostenible con los poderes autónomos de la región administrativa especial. Este equilibrio tiene un carácter dinámico e implica un balance de variados factores en diferentes asuntos. La fórmula "un país, dos sistemas" involucra, por ende, tanto la innovación constitucional como la sabiduría política. Una fórmula polarizada no funciona. El solo diálogo y la cooperación sin análisis crítico plantean el riesgo de poner en peligro valores 
e intereses fundamentales de cada lado. Un enfoque centrado exclusivamente en pesos y contrapesos y en confrontación no daría como resultado más que una crisis constitucional.

Al descifrar las tensiones constitucionales en Hong Kong, un foco común ha estado en la economía política de las interacciones entre las fuerzas prorrégimen y prodemocracia, con limitada literatura dedicada al estudio de las diferencias jurídico-culturales a lo largo del espectro político, considerando que el debate involucra un tópico tan políticamente sensible como el desarrollo del sufragio universal. El propósito de este artículo es colmar este vacío desarrollando una evaluación imparcial de la convergencia y divergencia de normas jurídicas chinas y del common law en el contexto de la reforma electoral de Hong Kong.

La divergencia en doctrina constitucional, a pesar de ser altamente compleja en su manifestación, puede ser articulada con simpleza. La perspectiva china acoge el principio fundamental de delegación de poder, según el cual los poderes autónomos de Hong Kong son conferidos por Beijing. Tales poderes deben ser ejercidos en el entendido de que Beijing retiene plenos poderes para invalidarlos. En otras palabras, se retiene la discrecionalidad soberana y "dos sistemas" deben someterse a "un Estado", en asuntos excluidos de la autonomía de Hong Kong. La perspectiva liberal, por otro lado, postula un marco constitucional basado en la división del poder, siendo la Ley Básica el instrumento supremo en la fijación de límites a la autonomía y al involucramiento soberano en asuntos de Hong Kong. Desde la perspectiva liberal, Beijing está constreñido por la Ley Básica y no puede transgredirla, no obstante su posición como soberano ${ }^{24}$.

En otras palabras, desde la perspectiva jurídica china, mientras las reglas procedimentales sean observadas, Beijing puede ejercer amplios poderes soberanos en Hong Kong. Esta concepción es evidente en la interpretación de la Ley Básica que ha hecho el Comité Permanente en el pasado. De acuerdo con el artículo 158(1) de la Ley Básica y el artículo 67(4) de la Constitución china, el Comité Permanente goza de un poder independiente para interpretar la Ley Básica. Esta posición ha sido confirmada por la decisión del Tribunal de Última Instancia en Lau Kong Yung v. el Director de Inmigración ${ }^{25}$. En la

24 Para una discusión profundizada sobre este punto, Delisle; Lane (2004), p. 1469.

25 Lau Kong Yung v. el Director de Inmigración [1999] 3 HKLRD 778. A modo de aclaración para el lector no familiarizado con el sistema de citación de jurisprudencia de Hong Kong, éste se estructura a partir de los siguientes elementos: (i) la enunciando el nombre completo de las partes en cursivas, separadas 
medida que el Comité Permanente siga las reglas y principios que rigen sus poderes interpretativos, la interpretación resultante deberá tener el mismo efecto jurídico que la legislación ${ }^{26}$. La perspectiva liberal, empero, ve más allá del positivismo legal y sostiene su posición en el Estado de derecho. En su perspectiva, lo que más importa es que la supremacía del derecho y el selfrestraint soberano sean efectivos, si la promesa de un alto grado de autonomía se ha de tomar en serio ${ }^{27}$.

Un clásico ejemplo de colisión de tradiciones constitucionales es la controversia sobre la interpretación de la Ley Básica. Según la doctrina china, siendo el Comité Permanente el más alto órgano del poder estatal, éste posee la autoridad legítima para interpretar la constitución y las normas nacionales, incluyendo la Ley Básica ${ }^{28}$. Según el common law, sin embargo, la judicatura interpreta la legislación de acuerdo con principios de interpretación asentados. La interpretación legal emanada de un órgano político o legislativo es inconcebible desde la perspectiva del common law. La divergencia surge de comprensiones diversas sobre la estructura del poder estatal y el rol de los distintos órganos en la arquitectura constitucional ${ }^{29}$.

Esta significativa divergencia entre convicciones ideológicas y valores legales de ambos sistemas contribuye considerablemente a impedir que las dos coaliciones logren un consenso. La división no puede ser superada simplemente por medios políticos. Sin una comprensión profunda de la doctrina china sobre la Ley Básica, cualquier predicción sobre la postura de Beijing respecto del sufragio universal permanece en la pura especulación política ${ }^{30}$. Análogamente,

con una "v", (ii) el año -en paréntesis cuadrado si el año de la publicación hace las veces de volumen de publicación, o en paréntesis redondos si existe un número de volumen separado-, (iii) el volumen, si corresponde, (iv) el título abreviado de la publicación en la que el caso es publicado, (v) la primera página del caso y (vi) la página referenciada. Las abreviaturas que aquí se emplean se refieren a las siguientes publicaciones: Hong Kong Law Reports \& Digest (HKLRD); Hong Kong Public Law Reports (HKPLR); Law Reports: Appeal Cases (AC).

26 Feng (2001), p. 37.

27 CHen (2007), p. 446.

28 Para una evaluación jurisprudencial del poder del Comité Permanente para interpretar la Ley Básica, véase Lin; Gu (2001-2002), p. 73.

29 CHen (2002), pp. 232 y s.

30 El debate académico de Hong Kong gradualmente se enfoca más en la doctrina china dada su importancia en el desarrollo del constitucionalismo en Hong Kong. Fu; Young (2007), p. 8. 
evaluar únicamente las motivaciones políticas de la Coalición de Oposición sin develar los argumentos jurídicos subyacentes en que sustentan su pretensión de mayor democracia también parcializaría la investigación. El derecho constitucional no sólo tiene que ver con política. El enfoque de economía política como metodología de trabajo para explicar la interacción entre los dos sistemas tiene sus méritos ${ }^{31}$. Con todo, esta metodología no puede explicar plenamente la tensión inherente de los dos sistemas originados a partir de la divergencia de valores doctrinarios. Un estudio imparcial del conflicto de normas constitucionales y legales provee una perspectiva original sobre el tópico del desarrollo del sufragio universal bajo "un país, dos sistemas". Igualmente útil es el estudio general del contenido constitucional y el procedimiento de la Ley Básica. Sólo en este plano es posible que ambos sistemas puedan entablar un diálogo y concretar puntos de encuentro que suavicen la interacción y prevengan una crisis ${ }^{32}$.

Sobre la cuestión del sufragio universal, el artículo 25(b) del PIDCP figura prominentemente en el debate. La extensión del PIDCP a Hong Kong por Gran Bretaña estuvo sujeta a reserva del derecho a no aplicar el artículo 25(b), toda vez que podía requerir el establecimiento de un Consejo Ejecutivo o Legislativo en Hong Kong. En términos simples, el punto es si el artículo 25(b) aplica a Hong Kong en la actualidad, dado que las circunstancias han cambiado, pues Hong Kong ya cuenta con una legislatura electa y podría tener un Jefe Ejecutivo electo en el futuro. El asunto es importante porque si el artículo aplica y la reserva ya no es efectiva, las reformas electorales de Hong Kong deben cumplir con los requerimientos internacionales dispuestos en el artículo 25(b). Si el artículo 25(b) no aplica, la legislación y normativa doméstica dominaría la estructura suprema del sistema. Se sigue que hay mayor margen para discutir una forma alternativa de sistema electoral en el futuro.

\footnotetext{
31 Siguiendo a Ghai, quien ha adoptado el enfoque de economía política, la interacción entre los dos sistemas puede ser explicada de mejor modo atendiendo a las fuerzas políticas tras cada sistema legal en lugar de a la superioridad de cada sistema legal. Él concluye que pese a ser más débil en su sistema jurídico, el sistema legal chino, mediante la destreza política que le subyace, ha triunfado sobre el sistema del common law. Cfr. GHaI (2007), pp. 365-367.

32 Chang (2007), p. 362.
} 


\section{ANÁlisis COMPARATIVO SOBRE LA DOCTRINA CHINA Y DEL COMMON LAW SOBRE LA LEY BÁSICA}

\subsection{Fundamentos de la doctrina china sobre la Ley Básica}

Hong Kong es una región bajo el sistema unitario de China. Los marcos constitucionales según la Ley Básica poseen el carácter esencial de un régimen de traspaso de poderes desde Beijing a Hong Kong 33 . Éste no tiene, por tanto, poderes autónomos o soberanos ${ }^{34}$.

Sin tratarse de una estructura federal, la fórmula "un país, dos sistemas" posee características que se apartan sustancialmente del sistema unitario tradicional. Desde la perspectiva de la soberanía, la fórmula cae decisivamente en la categoría unitaria, en la que el gobierno central posee poderes plenos ${ }^{35}$. Los poderes de Hong Kong son delegados por el Gobierno Popular Central y en consecuencia no califican como poderes autónomos ${ }^{36}$. Pero, desde la perspectiva de la autonomía, la fórmula "un país, dos sistemas" posee rasgos de una estructura federal ${ }^{37}$. Aunque el Gobierno Central maneja asuntos de política exterior, se reconocen amplios poderes a Hong Kong en la conducción de sus propios asuntos (Capítulo VII de la Ley Básica).

Siguiendo la lógica de este régimen de traspaso de poder, el Jefe Ejecutivo de Hong Kong es responsable ante el Gobierno Central (artículo 43 de la Ley

33 WANG; LEUNG (1998), p. 299.

34 Wu Bangguo, expresidente del Congreso Popular Nacional, ha señalado que "[Hong Kong] only has as much power as authorized by the central government. There is no so-called residual power". ZHE (2007).

35 ZHu (2006), pp. 85 y ss.

36 Siming explica que hay cuatro características fundamentales que distinguen a la configuración de la región administrativa especial de una típica configuración federal:

(i) Hong Kong no posee una constitución propia. La Ley Básica es sólo un instrumento sujeto a la constitución del Gobierno Popular Central (en un Estado unitario sólo puede haber una constitución, la cual es la constitución nacional).

(ii) Hong Kong no tiene poderes soberanos.

(iii) Hong Kong no participaría en la política nacional como un miembro constituyente de un Estado federal lo haría (e. g. siendo representado un Estado en la cámara alta de la legislatura nacional).

(iv) Hong Kong no tiene autoridad para confrontar al Gobierno Popular Central toda vez que los poderes de que goza Hong Kong son conferidos por aquél. Esto se distingue del sistema federal en el que el poder está dividido entre el centro federal y los Estados constituyentes.

Cfr. Siming (1997), pp. 69 y ss.

37 ZHu (2006), pp. 85 y ss. 
Básica). Resulta también que un alto grado de autonomía no implica completo aislamiento o marginación. Cuando se trata de asuntos importantes que no están sólo dentro del dominio de la autonomía de Hong Kong, como la reforma electoral, Beijing desempeña un rol crítico.

\subsection{Limitaciones de la doctrina china}

Aunque la doctrina sobre la Ley Básica es considerablemente sistemática, es importante reflexionar acerca de sus limitaciones. Ghai ${ }^{38}$, por ejemplo, apunta que China carece de una teoría coherente de la autonomía y que aún no ha desarrollado un mecanismo sofisticado para manejar las reivindicaciones de autonomía. Hay razones históricas y causas más recientes para estas deficiencias.

China ha estado unida bajo un gobierno central desde el año $221 \mathrm{~d}$. C. y se ha mantenido unida por la mayor parte del tiempo a lo largo de su historia. Pese a que ha habido tiempos de guerra y división, la unificación del "Reino del Medio" siguió siendo la norma y ha sido la causa legítima de innumerables movimientos políticos que mantuvieron el ciclo dinástico en marcha. El colosal sistema administrativo establecido en China por más de 2000 años había sido efectivo $\mathrm{y}$, de hecho, altamente innovador en términos de las prácticas políticas vigentes al tiempo de su creación y por muchos años después. Sin embargo, el sistema no evolucionó adecuadamente. Las experiencias occidentales de organización del poder estatal, particularmente las estructuras constitucionales y la teoría de la descentralización del poder han sido el resultado de siglos de experimentación política conducida en un contexto histórico muy distinto al de China. Rezagada tanto en teoría como en práctica, China dejó su inercia y comenzó a desarrollar sus propias teorías constitucionales a fines del siglo XIX y a principios del siglo XX. Pese a estos esfuerzos, la preferencia tradicional por la administración centralizada y la valoración de la unificación del país como un imperativo cuasimoral aún están profundamente enraizados en la cultura política china. Esta cultura única sigue estando muy viva en la China contemporánea donde el vocero oficial defiende fervientemente la indivisibilidad de la soberanía bajo la estructura estatal unitaria de China. El desarrollo de la teoría constitucional sobre la autonomía ha sido limitado.

38 GHAI (1999), pp. 123 y ss. 
Otra línea de crítica cuestiona el enfoque estrictamente positivista adoptado en la interpretación constitucional de la Ley Básica. En este sentido, Xingzhong 39 explica el enfoque positivista chino empleando el concepto de formalismo constitucional y observando que este enfoque tiene limitaciones inherentes si no se respetan debidamente los compromisos constitucionales sustantivos.

La doctrina constitucional china según la cual la soberanía es indivisible y sobre el énfasis en la naturaleza unitaria del Estado chino torna cualquier marco regional autónomo en el resultado de un traspaso unidireccional del gobierno central. Desde la perspectiva liberal, esta matriz inflexible de autonomía obstaculiza la creatividad constitucional y se convierte en un obstáculo en la búsqueda de Hong Kong de una mayor democracia. Cualquier reestructuración constitucional en Hong Kong permanece como un asunto a ser decidido por Beijing como árbitro supremo. Al mantener una "visión tradicional" de la soberanía y la autonomía, Beijing no aceptará ninguna forma de constitucionalismo pospolítica, deviniendo así inaplicable a la situación de Hong Kong la multiplicidad de herramientas disponibles en el constitucionalismo posmoderno ${ }^{40}$.

\subsection{Bases de la doctrina liberal y del common law sobre la Ley Básica}

El discurso liberal acerca de la Ley Básica postula una serie de consideraciones importantes que apuntan a mantener un "alto grado autonomía" y defender los valores fundamentales del sistema jurídico de Hong Kong, tales como el Estado de derecho y un régimen robusto de protección de los derechos humanos. Estos objetivos pueden ser alcanzados tratando al nuevo orden constitucional como un sistema autocontenido bajo el cual los poderes están claramente divididos entre el Gobierno Central y Hong Kong. El éxito de tal ordenación también depende de si las instituciones para la autonomía de Hong Kong, particularmente las cortes, son capaces de operar libres de interferencia política. Aunque reconociendo que la autonomía tiene sus límites, el discurso liberal se enfoca primariamente en el self-restraint soberano y el compromiso

\footnotetext{
39 XingZHong (2009), p. 183.

40 Neil Walker resume correctamente la fuerte resistencia contra la búsqueda de un constitucionalismo postestatal inherente a las bases ideológicas del constitucionalismo tradicional centrado en el Estado. Cfr. WALKER (2008), p. 522.
} 
con un alto nivel de autonomía de Hong Kong. Tal compromiso se demuestra de mejor manera cuando Beijing se considera a sí mismo limitado por la Ley Básica y no transgrede la competencia de la miniconstitución de Hong Kong en sus acciones relacionadas con éste.

La postura liberal es que la autonomía no puede ser resguardada sin un fuerte régimen jurídico aislado de la manipulación política y por tanto la independencia judicial no sólo ha sido considerada como crucial, sino como indispensable. Las cortes generalmente han sido robustas en la defensa de los derechos y en la preservación del Estado de derecho. Desde la perspectiva liberal, el artículo 158 de la Ley Básica debía operar a favor de la maximización de la autonomía. Corresponde al exclusivo dominio de la Corte de Última Instancia decidir si se busca la interpretación de disposiciones relevantes de la Ley Básica en el Comité Permanente. He aquí por qué el discurso liberal se opone vehementemente a la interpretación que hace el Comité Permanente de la Ley Básica, la cual es vista como una peligrosa intromisión en la autonomía de Hong Kong bajo los ropajes del formalismo constitucional ${ }^{41}$. En esta visión, la falta de reglas claras de interpretación y la ausencia de razonamiento jurídico escrito en las interpretaciones del Comité Permanente han tornado el futuro de la autonomía Hong Kong tan impredecible como frágil ${ }^{42}$.

Respecto de la reforma electoral, la postura liberal promovía el involucramiento mínimo de Beijing. Se formularon argumentos jurídicos para asegurar que Hong Kong pudiera ejercer plenamente sus derechos autónomos en la determinación de su futuro constitucional. Por ejemplo, en relación con la reforma del método para formar el Consejo Legislativo, los requerimientos eran un apoyo de los dos tercios del Consejo Legislativo, el consentimiento del Jefe Ejecutivo y reportar la enmienda al Comité Permanente para "su registro" (Anexo II, artículo $3^{\circ}$ de la Ley Básica). Se sostuvo que dado que no se requería "aprobación" del Comité Permanente, la reforma en la elección del Consejo Legislativo podía ser conducida enteramente como un asunto local en que el gobierno central no tuviera un rol sustancial ${ }^{43}$. La realidad, por supuesto, era muy distinta a la expectativa liberal.

\footnotetext{
41 GHai (2004).

42 GHAI (2007), pp. 399 y s.

43 GHaI (1999), p. 177.
} 


\subsection{Limitaciones al discurso liberal}

Un argumento conservador es que la postura liberal no ha considerado debidamente la dimensión de "un país" de la fórmula constitucional ${ }^{44}$. Su éxito requiere un cuidadoso balance entre la discreción soberana y los poderes autónomos. Centrarse completamente en los "dos sistemas" plantea el riesgo de descuido de las inquietudes constitucionales chinas. La doctrina constitucional de China es lo que es. Sería irrealista esperar un cambio en la teoría fundamental china sobre la autonomía regional de la noche a la mañana ${ }^{45}$. Lo que se puede hacer, sin embargo, es estudiarla minuciosamente y tratar de encontrar vías para alcanzar un acuerdo.

Es justo decir que las autoridades centrales han ejercido bastante self-restraint en varios aspectos al preservar la autonomía de Hong Kong. Estos son esfuerzos genuinos que precisan ser reconocidos. El ejercicio de los poderes de Hong Kong en materia de relaciones exteriores alcanzo su cénit en el manejo del trágico incidente de rehenes en Manila en agosto de 2010. Donald Tsang, Jefe Ejecutivo de Hong Kong en esa época, hizo contacto directo con el presidente filipino sin pasar por el Ministro de Relaciones Exteriores de China. Pese a atraer fuertes críticas de quienes sostenían que el Jefe Ejecutivo no tenía tales poderes, la acción de Tsang fue recibida con la aquiescencia de Beijing. Este incidente demuestra el amplio alcance de la autonomía que Hong Kong posee en la conducción de sus asuntos exteriores.

\section{ANÁlisis COMPARATIVO DE LA DOCTRINA CHINA Y DEL COMMON LAW SOBRE LA INTERNACIONALIZACIÓN DEL DERECHO CONSTITUCIONAL EN} Hong Kong y la aplicabilidad del artículo 25(B) Del PIDCP

\subsection{Perspectiva china sobre la internacionalización del régimen constitucional de derechos humanos en Hong Kong}

La doctrina china es categóricamente contraria al concepto de internacionalización del régimen de derechos humanos en Hong Kong. La Ley Básica es el documento constitucional supremo en Hong Kong y ningún tratado internacional

\footnotetext{
44 Nótese que el objetivo de la fórmula "un país, dos sistemas" fue la reunificación de China. "Dos sistemas" es sólo un medio necesario para lograr el objetivo de "un país”. WANG; LeUnG (1998), p. 284.

45 Por ejemplo, sería irrealista esperar que Beijing acepte que Hong Kong posee poderes autónomos. Tal expectativa revela una completa desatención a la teoría constitucional china.
} 
puede estar por sobre la Ley Básica. Esta es una de las razones que explican la limitada aplicación de la Ordenanza sobre la Carta de Derechos (OCD) -cuerpo normativo a través del cual se incorpora el PIDCP al ordenamiento jurídico interno- en Hong Kong. En efecto, tras la devolución en 1997, las disposiciones interpretativas fundamentales que daban precedencia a la misma sobre otras normas legislativas, preexistentes o subsiguientes ${ }^{46}$, no fueron adoptadas ${ }^{47}$. En particular, la decisión de no adoptar la sección 2(3) de la OCD reflejaba la clara intención de Beijing de rechazar la internacionalización del régimen de derechos humanos de Hong Kong ${ }^{48}$.

La posición contra la internacionalización del régimen de derechos humanos en Hong Kong es sin duda sostenible si se asume un enfoque positivista en la interpretación del artículo 39 de la Ley Básica y en el texto sobreviviente de la OCD. El artículo 39 específicamente prescribe que el PIDCP "en cuanto se aplique a (as applied to) Hong Kong permanecerá en vigor y será implementado a través de las leyes de la Región Administrativa Especial de Hong Kong”. En el texto chino de la Ley Básica las palabras "en cuanto se aplique" (as applied) del artículo 39 en realidad significan "aplicable". Como el texto chino de la Ley Básica prevalece sobre el texto en inglés, se sigue el argumento según el cual existen disposiciones del PIDCP que no aplican a Hong Kong. En la medida que esas disposiciones son aplicables a Hong Kong, ellas no adquieren eficacia hasta que son implementadas mediante legislación local. Shuwen ${ }^{49}$ observa que "Los dos pactos [el PIDCP y el PIDESC] no son directamente aplicables a Hong Kong ni tienen fuerza normativa directa en Hong Kong”. De este modo, la perspectiva china sobre el punto puede ser resumida como sigue:

a) La Ley Básica de Hong Kong es la norma fundamental para la protección de los derechos humanos en Hong Kong. Todos los instrumentos relativos a los derechos humanos aplicables a Hong Kong están sujetos a la Ley Básica.

46 Las disposiciones no adoptadas como leyes de Hong Kong fueron las secciones 2(3), 3(1), 3(2) y 4 de la OCD.

47 Luego de la devolución, ejerciendo la atribución establecida en el artículo 160 de la Ley Básica, el Comité Permanente determinó que las referidas disposiciones interpretativas eran contrarias a la Ley Básica. Chen (2002), p. 244.

48 La sección 2(3) de la OCD prescribe: "En la interpretación y aplicación a esta Ordenanza, respeto deberá ser dado al hecho de que el propósito de esta Ordenanza es disponer la incorporación al derecho de Hong Kong de disposiciones del Pacto Internacional de Derechos Civiles y Políticos en cuanto se apliquen a Hong Kong, y para asuntos complementarios y conexos".

49 SHUWEN (2006), p. 203. 
b) El artículo 39 de la Ley Básica no otorga estatus constitucional al PIDCP. Sólo aquellas disposiciones que fueran aplicables a Hong Kong antes de la devolución deben permanecer vigentes. Las disposiciones aplicables a Hong Kong no poseen fuerza normativa directa y deben ser implementadas a través de legislación local.

c) La OCD no tiene un estatus especial en Hong Kong, ya que las disposiciones interpretativas clave que previamente le dieron precedencia sobre otras normas no fueron adoptadas como leyes de Hong Kong.

d) Si bien la OCD tuvo estatus constitucional en forma previa a la devolución, la disposición que le había conferido tal estatus -la constitución previa de Hong Kong o Carta Patente (Letters Patent)-, había devenido inoperativa por tratarse de legislación colonial.

No debería causar extrañeza que la postura conservadora sea contraria a la internacionalización del régimen de derechos humanos en Hong Kong dada la historia de la Ordenanza y el diseño estratégico de Gran Bretaña subyacente a su legislación. La promulgación de la OCD fue una respuesta a las inquietudes del pueblo de Hong Kong que se siguieron del Incidente de Tiananmen en 1989. Fue diseñada para proveer a Hong Kong de un régimen robusto de protección de los derechos humanos incorporando efectivamente al PIDCP en su legislación doméstica. Beijing era escéptico a su promulgación desde el mismo comienzo y estaba particularmente incómodo con el estatus constitucional conferido a ella, afianzado por el artículo VII(5) de la Carta Patente ${ }^{50}$.

La estrategia de internacionalizar el régimen de derechos humanos de Hong Kong funcionó muy bien. El afianzamiento de la OCD marcó el comienzo de la adjudicación constitucional en Hong Kong y estableció la práctica judicial de aplicar directamente el PIDCP y la OCD en la adjudicación constitucional. Como se demostrará más abajo, pese a todo, esta práctica sobrevivió a la devolución.

\subsection{Perspectiva del common law sobre la internacionalización del régimen constitucional de derechos humanos en Hong Kong}

Es difícil reconciliar la perspectiva china con el tratamiento judicial de la OCD y del PIDCP después de la devolución. La no adopción de las disposiciones interpretativas de la OCD no cambió la tradición de protección de los derechos

50 ByRnes (1999), p. 335. 
en Hong Kong tras 199751. En el fallo emblemático RAEHKv. $\mathrm{Ng}$ Kung Siü2, la Corte de Última Instancia confirmó la eficacia operativa de la OCD y del PIDCP en Hong Kong y su autoridad para invalidar legislación inconsistente con estos instrumentos de derechos humanos ${ }^{53}$. Ella interpretó el artículo 39 de la Ley Básica como fundamento del rango constitucional del PIDCP y del OCD ${ }^{54}$ ubicando así efectivamente a los dos instrumentos en la misma jerarquía normativa que la Ley Básica ${ }^{55}$. No ha de causar sorpresa que la Corte adoptara este enfoque en la interpretación de los derechos humanos. Desde el inicio de la adjudicación judicial subsiguiente al afianzamiento de la OCD, éste ha tratado a los preceptos sobre derechos humanos como un sui generis que requiere una generosa aproximación interpretativa ${ }^{56}$. Esta aproximación liberal y deliberada había sido confirmada por el Privvy Council y fue consistentemente aplicada en la adjudicación constitucional previa a la devolución ${ }^{57}$.

La postura liberal está claramente a favor de la internacionalización del régimen de derechos humanos, atendido particularmente su escepticismo hacia el compromiso de Beijing a la protección de los derechos humanos en Hong Kong ${ }^{58}$. En su perspectiva, la elevación del PIDCP al plano constitucional permite la directa aplicación de las normas internacionales de derechos humanos en Hong Kong y previene la burla de los derechos por parte de Beijing.

\subsection{Perspectiva china sobre la aplicabilidad del artículo 25(b) del PIDCP}

La discusión acerca de la aplicabilidad del PIDCP en Hong Kong resulta relevante en el marco de la discusión acerca de la implementación del sufragio universal, toda vez que su artículo 25(b) establece:

51 CHen (2002), p. 244.

52 [1999] 3 HKLRD 907.

53 Véase también Chan Wah v. Hang Hau Rural Committee [2000] 1 HKLRD 441 en 442.

54 El gobierno de Hong Kong, por otro lado, adopta una posición mucho más conservadora. TAI (2002), p. 581.

55 Chen (2002), pp. 244-246; TAI (2005), p. 7.

56 Rv. Sin Yau-ming (1991) 1 HKPLR 88.

57 Byrnes (1999), p. 357; Fiscal General de Hong Kong v. Lee Kwong Kut [1993] AC 951.

58 DaVIS (2007), p. 84. 
"Todos los ciudadanos gozarán, sin ninguna de la distinciones mencionadas en el artículo $2^{\circ}$, y sin restricciones indebidas, de los siguientes derechos y oportunidades: [...] b) Votar y ser elegidos en elecciones periódicas, auténticas, realizadas por sufragio universal e igual y por voto secreto que garantice la libre expresión de la voluntad de los electores".

La posición china sobre la aplicabilidad del artículo 25(b) del PIDCP en Hong Kong puede ser resumida como sigue:

a) No todas las disposiciones del PIDCP son aplicables a Hong Kong. El artículo 39 de la Ley Básica específicamente establece que sólo aquellas disposiciones del PIDCP "en cuanto se apliquen a Hong Kong” permanecerán en vigor después de la devolución ${ }^{59}$.

b) El artículo no es aplicable a Hong Kong como resultado de una reserva formulada por el Reino Unido al suscribir el PIDCP. Dado que dicha reserva no fue revocada, ella continúa en vigor después de la devolución, conforme al artículo 39 de la Ley Básica.

c) De acuerdo con el artículo 39, incluso aquellas disposiciones del PIDCP que sean aplicables a Hong Kong luego de la devolución requerirán ser implementadas mediante legislación local ${ }^{60}$.

d) En último término, si bien el artículo 21(b) de la OCD replica en lo sustancial el contenido del artículo 25(b)del PIDCP, la sección 13 de la misma establece que "El artículo 21 no exige el establecimiento en Hong Kong de un Consejo Ejecutivo o Legislativo electo". En este sentido, se incorpora una reserva al PIDCP en la legislación doméstica de Hong Kong.

Desde la perspectiva jurídica china, la discusión sobre el artículo 25(b) del PIDCP es cuestionable, ya que el sufragio universal ya es asegurado bajo los artículos $45^{61} \mathrm{y}$

59 CHEN (2002), p. 274.

60 Geping (2008), p. 452.

61 Artículo 45. "El Jefe Ejecutivo de la Región Administrativa Especial de Hong Kong será seleccionado por elección o a través de consultas realizadas localmente y será proclamado por el Gobierno Central Popular. El método para seleccionar al Jefe Ejecutivo será especificado a la luz de la actual situación de Región Administrativa Especial de Hong Kong y de acuerdo con el principio de progreso gradual y ordenado. El objetivo final es la selección del Jefe Ejecutivo por sufragio universal tras nominación por un comité nominador ampliamente representativo, conforme a procedimientos democráticos.

El método específico para seleccionar al Jefe Ejecutivo es prescrito en el Anexo I 'Método para la Selección del Jefe Ejecutivo de la Región Administrativa Especial de Hong Kong”". 
$68^{62}$ de la Ley Básica y un cronograma oficial para el sufragio universal fue establecido por la decisión del Comité Permanente de 2007. La Ley Básica, y no el PIDCP, debería ser la autoridad suprema en la determinación del contenido del sufragio universal en Hong Kong. Por otro lado, una fuerte posición sostenida por académicos continentales es que la opinión del Comité de Derechos Humanos sobre este punto -que por lo demás no es vinculante- y que la judicatura de Hong Kong -que tampoco puede revocar una reserva a un tratado internacional en el common law- no cambiarían el hecho de que el artículo 25(b) del PIDCP no tiene aplicación en Hong Kong63.

\subsection{Perspectiva liberal sobre la aplicabilidad del artículo 25(b) del PIDCP}

La postura liberal cuestiona que la reserva en relación con el artículo 25(b) del PIDCP sea compatible con los objetivos y propósitos del PIDCP. Ghai observa que "[1]a inaplicación de los derechos a sufragio y a una legislatura y un ejecutivo electo impacta las raíces del Pacto, por cuanto niega las bases mismas de la democracia, sobre la que se puede sostener la existencia de otros derechos"64. Él argumenta asimismo que el derecho y la oportunidad para participar en la vida pública, conforme al artículo 21 de la OCD, no deben ser limitados sobre bases discriminatorias ni por restricciones "irrazonables" 65.

62 Artículo 68. "El Consejo Legislativo de la Región Administrativa Especial de Hong Kong se constituirá por elección.

El método para formar el Consejo Legislativo será especificado a la luz de la actual situación de Región Administrativa Especial de Hong Kong y de acuerdo con el principio de progreso gradual y ordenado. El objetivo final es la elección de todos los miembros del Consejo Legislativo por sufragio universal.

El método específico para formar el Consejo Legislativo y su procedimiento de votación de mensajes y mociones son prescritos en el Anexo II 'Método para la Formación del Consejo Legislativo de la Región Administrativa Especial de Hong Kong y su Procedimiento de Votación’”.

63 Contrástese la posición china con las posturas del Juez Keith en Lee Miu Ling v. Attorney General (No 2) (1995) 5 HKPLR 181. Véase también GEPING (2008), pp. 452-455.

"También está bien establecido que en la interpretación de las disposiciones de la Carta de Derechos puede obtenerse orientación de las decisiones de tribunales supra-nacionales, como el Comité de Derechos Humanos de las Naciones Unidas, y de los tribunales domésticos en jurisdicciones como Canadá que tienen una carta de derechos constitucionalmente afianzada, de los registros de la historia de la redacción del PIDCP, y de las posiciones de distinguidos comentaristas de tanto el PICDP como del derecho de los derechos humanos".

64 GHAI (1993), p. 166.

65 Ibíd. 
Por lejos, uno de los argumentos más fuertes desde el punto de vista liberal es que el artículo 21(b) de la OCD ha efectivamente incorporado al artículo 25(b) del PIDCP a las leyes de Hong Kong, no obstante la reserva. Más aún se sostiene que la sección 13 de la OCD es inoperativa, al menos en cuanto al Consejo Legislativo concierne, dado que Hong Kong ya tiene una legislatura electa.

Argumentando sobre la alternativa, siguiendo la jurisprudencia que ha establecido un enfoque generoso y positivo para la interpretación de la Ordenanza, y dando al mismo tiempo pleno reconocimiento a los objetivos del PIDCP66, la posición liberal es que la sección 13 de la OCD no puede ser aplicada para frustrar los verdaderos objetivos del artículo 25(b) del PIDCP y ciertamente no como justificación para implementar marcos electorales injustos.

Adicionalmente se ha sugerido que, ya que la presunción bajo el common law es que la legislatura no pretende actuar en infracción del derecho internacional, es inconcebible que el Consejo Legislativo tuviera la intención de convertir la sección 13 de la OCD en un instrumento para impedir a Hong Kong cumplir con el artículo 25(b) PIDCP, considerando que las circunstancias políticas contempladas en la sección 13 ya no son efectivas ${ }^{67}$.

\subsection{Jurisprudencia sobre el artículo 25(b) del PIDCP $y$ algunas predicciones}

Una serie de casos previos y posteriores a la devolución han considerado la aplicabilidad del artículo 25(b) del PIDCP en Hong Kong.

En Lee Miu Ling v. Fiscal General ${ }^{68}$, los demandantes buscaban que se declarara que las disposiciones legislativas relativas a las circunscripciones funcionales infringían el principio de "una persona, un voto" y por tanto violaban el artículo 21(b) de la Carta de Derechos de Hong Kong que garantizaba el derecho a sufragio igualitario. El Tribunal Superior sostuvo que ese artículo requería que cada residente permanente de Hong Kong tuviera el derecho a votar en la elección de los miembros del Consejo Legislativo y a ser efectivamente representado por los miembros elegidos en las respectivas circunscripciones. Adicionalmente, el derecho a sufragio igualitario requería que cada residente permanente tuviera el

\footnotetext{
66 R v. Sin Yau-ming (1991) 1 HKPLR 88; Attorney-General of Hong Kong v. Lee Kwong Kut [1993] AC 951; Lee Miu Ling v. Attorney General (1995) 5 HKPLR 181.

67 GHAI (1993), p. 166.

68 Lee Miu Ling v. Attorney General (1995) 5 HKPLR 181.
} 
mismo poder de voto y a que se le concediera votos de igual peso en tales elecciones. Al tratar con la cuestión sobre si la sección 13 de la OCD que incorporaba la reserva efectivamente restringía el artículo 21(b) de la Carta de Derechos de Hong Kong, el juez Keith sostuvo:

"Dado que la Carta Patente ahora requiere el establecimiento de un Consejo Legislativo electo, la sección 13 de la Ordenanza de Carta de Derechos es, en cuanto se vincula con el Consejo Legislativo, letra muerta hasta que la Carta Patente sea reformada para remover el requerimiento de un Consejo Legislativo electo. Esa es la razón por la que la sección 13 no puede ser empleada ahora para justificar un alejamiento de los derechos garantizados por el artículo 21 de la Ordenanza sobre la Carta de Derechos [...] Por consiguiente, sujetos a la Carta Patente, los derechos garantizados por el artículo 21 de la Ordenanza sobre la Carta de Derechos aplican a las elecciones del Consejo Legislativo".

Pese a juzgar a la reserva como "letra muerta", la Corte se rehusó a declarar que el artículo VII(3) de la Carta Patente expresamente permitiera la expedición de normas que confirieran a un número limitado de personas el derecho a votar en circunscripciones tanto funcionales como geográficas y que el artículo VII(5), que confería a la OCD estatus constitucional, no impidiera que ninguna parte de la Carta Patente derogara los derechos garantizados por la OCD ${ }^{69}$. El Tribunal de Apelaciones ${ }^{70}$ desechó la apelación y confirmó la base sobre la cual el Tribunal Superior rehusó emitir la referida declaración -en orden a que el artículo VII(3) de la Carta Patente permitía la expedición de las provisiones legales cuestionadas- pero no expresó ninguna opinión sobre el obiter del juez Keith en cuanto a que la reserva se había convertido en letra muerta ${ }^{71}$.

Las autoridades posdevolución jamás se acercaron a las posiciones liberales expresadas por el juez Keith en Lee Miu Ling. En Chan Wah v. Comité Rural Hang Hau ${ }^{72}$, la Corte de Apelaciones (en obiter) parecía haber reconocido que

69 Para una crítica al razonamiento del tribunal en relación con la Carta Patente, véase Young (1997), pp. 712 y ss.

70 Lee Miu Ling v. Attorney General (1995) 5 HKPLR 181.

71 El Tribunal de Apelaciones rechazó el argumento de los "dolores de crecimiento" en cuanto a que el sistema electoral de Hong Kong se encontraba en una etapa embriónica y que debía ser juzgado benévolamente y con menos rigurosidad. La razón para desechar el argumento era que el caso refería a "si una desigualdad en el sufragio se había o no abierto camino en el actual sistema electoral de Hong Kong y no a cómo ese sistema podía evolucionar en el futuro".

72 Chan Wah v. Hang Hau Rural Committee (2000) 1 HKLRD 411. 
la reserva relativa a un Consejo Legislativo electo era efectiva, pero dejó en claro que el artículo 21(b) de la Carta de Derechos de Hong Kong era aplicable a las elecciones públicas a nivel regional y local ${ }^{73}$. El caso más tarde fue apelado ante la Corte de Última Instancia, pero ésta no discutió el asunto de la reserva. Una posición conservadora fue adoptada por el Tribunal Superior en Chan Yu Nam v. Ministro de Justicia ${ }^{74}$ en el que se resolvió que el voto corporativo en elecciones para circunscripciones funcionales no contravenía la Ley Básica ni el artículo 21(b) de la OCD de Hong Kong75. Haciendo presente que la oportunidad era de "crucial importancia", el Tribunal parecía haber tomado la posición de que, dado que la reserva estaba operativa al tiempo de la promulgación de la Ley Básica, la legislatura china debía haber pretendido que la reserva fuera efectiva después de 199776 .

La cuestión pertinente es si a futuro las cortes estarán preparadas para invocar directamente el artículo 25(b) en la determinación del asunto del sufragio universal. De ser así, ¿cuál sería su enfoque al interpretar el artículo? Una impugnación constitucional es muy probable si las futuras configuraciones electorales no satisfacen las expectativas del pueblo de Hong Kong. Como ya se discutió, los tribunales han adoptado un enfoque cauteloso respecto de este asunto luego de la devolución. Pero nadie puede predecir lo que probablemente ocurrirá si el asunto llega a la Corte de Última Instancia. ¿Revivirá el Tribunal su momento $\mathrm{Ng} \mathrm{Ka} \mathrm{Ling?} \mathrm{¿O} \mathrm{exhibirá} \mathrm{el} \mathrm{Tribunal} \mathrm{deferencia} \mathrm{judicial?} \mathrm{Considerando} \mathrm{que} \mathrm{el}$ razonamiento judicial en Chan Yu Nam tiene méritos, es discutible que un tribunal esté dispuesto a tratar la reserva como ineficaz, particularmente si hacerlo resultaría en la invalidación de una configuración electoral que tanto Beijing como Hong Kong promovieron asumiendo que habría un progreso político en algún punto en el futuro. Inquietudes surgidas de la dificultad mayoritaria también serían relevantes en la decisión de las cortes. Asumiendo que éstas promovieran la postura de la "letra muerta", quedaría todavía pendiente la cuestión acerca de

\footnotetext{
73 Ibíd., pp. 433-434 y 442.

74 Chan Yu Nam v. Secretary of Justice HCAL 32 y 55/2009.

75 "Por las razones dadas, en mi opinión, es bastante claro que el Congreso Popular Nacional nunca ha pretendido que el artículo 26 de la Ley Básica y que el artículo 25(b) del PIDCP (en cuanto se aplique a Hong Kong) haya de tener el efecto de prohibir el voto corporativo en las elecciones para las circunscripciones funcionales”, $\$ 118$.
}

76 Ibíd., $\$ \$ 116-117$. 
si las restricciones impuestas a futuras configuraciones electorales serían razonables y proporcionadas ${ }^{77}$.

\section{CONSIDERACIONES DE ECONOMÍA POLÍTICA EN TORNO AL SUfragio Universal EN Hong Kong \\ 6.1. Circunscripciones funcionales ¿Una panacea para la "participación equilibrada"78?}

La economía política de las circunscripciones funcionales en Hong Kong es sorprendentemente simple. Hong Kong tiene una fuerza política severamente subdesarrollada como para que su sector empresarial enfrente los desafíos de la política electoral. Los intereses empresariales han sido fuertemente afianzados en las instituciones existentes tan solo porque la infraestructura política de Hong Kong tiene un fuerte prejuicio a favor del sector empresarial. La tradición colonial de nombrar a líderes empresariales en las cámaras de poder del gobierno fue traspasada a Hong Kong. Esta seguridad política fue todavía más afianzada con la introducción de las circunscripciones funcionales en 1985. Beijing considera al sector empresarial como un importante fuerte en la mantención de la estabilidad de Hong Kong. Las bases ideológicas del capitalismo y el estatus de aquél como centro financiero internacional ha movido a los arquitectos gubernamentales a acoger valores elitistas y tolerar el predominio empresarial. Esto era cierto para Gran Bretaña en el pasado y sigue siendo cierto para Beijing hoy. Si la abolición de las circunscripciones funcionales significaran un golpe fatal o sustancial en la representación política del sector empresarial en Hong Kong, las circunscripciones funcionales probablemente serían preservadas en una forma u otra para asegurar la "participación equilibrada de todos los grupos y sectores de la sociedad"79.

Si bien la inmadurez política del sector empresarial es un factor que contribuye significativamente al afianzamiento de las circunscripciones funcionales en

\footnotetext{
77 Secretary of Justicia v. Chan Wah [2000] 3 HKLRD 641; Chan Yu Nam v. Secretary of Justice HCAL 32 y 55/2009 (10 de diciembre de 2009); Chan Kin Sum v. Secretary of Justice [2009] 2 HKLRD 166.

78 La idea de "participación equilibrada" fue introducida en la Decision of the Standing Committee of the National People's Congress on Issues Relating to the Methods for Selecting the Chief Executive of the Hong Kong Special Administrative Region in the Year 2007 and for Forming the Legislative Council of the Hong Kong Special Administrative Region in the Year 2008.

79 Ibíd.
} 
la infraestructura electoral de Hong Kong, una perspectiva mucho más amplia es necesaria para apreciar la profundidad de este problema. Una anomalía clave de la política electoral de Hong Kong contribuyó a este problema. Ésta se había desarrollado bajo circunstancias históricas muy distintas en comparación con el Occidente. En las democracias occidentales, las políticas partidistas se habían desarrollado en una etapa en que las fuerzas políticas estaban perfectamente ordenadas en un espectro basado principalmente en factores socioeconómicos más que en pura ideología política ${ }^{80}$. La razón de este fenómeno fue que el desarrollo de los partidos en el Occidente alcanzó su cúspide en una época de privación de derechos de la clase trabajadora en la era industrial ${ }^{81}$. En Hong Kong, sin embargo, dos factores impidieron la formación de los partidos en la línea occidental. En la época en que las elecciones competitivas fueron introducidas en Hong Kong a principios de los noventa, la ciudad ya estaba en su era posindustrial. No había un movimiento equivalente de clases desde abajo en la formación de la tradición electoral de Hong Kong82. Otro factor es el "secuestro" de la agenda política por la "cuestión de 1997" que resultó en una división política entre la Coalición Pro Gobierno y la Coalición de Oposición, una división basada, no en diferencias de política socioeconómica, sino en rivalidad ideológica. Bajo estas circunstancias, es difícil que los intereses socioeconómicos de los diversos sectores de Hong Kong encuentren un foro partidista apropiado para expresarse. Es aún más difícil para una agenda sectorial hacerse camino en la política dominante en Hong Kong. Las circunscripciones funcionales se convirtieron en la interfaz política -con un bajo requerimiento de ingreso- para causas socioeconómicas.

La doctrina de Hong Kong sobre el futuro de las circunscripciones funcionales es particularmente digna de atención dada la creatividad de las soluciones ofrecidas. Por ejemplo, la propuesta de transformar las actuales circunscripciones funcionales en una cámara legislativa alta ha recibido algo de apoyo de la comunidad $^{83}$. Dicha propuesta efectivamente cambia la estructura legislativa de Hong Kong del unicameralismo al bicameralismo. Sin embargo, el alcance

\footnotetext{
80 Si bien hay desacuerdos partidistas sobre toda clase de asuntos (no sólo limitados a los socioeconómicos), las "divisiones políticas" han definido la Izquierda y Derecha en el Occidente. Véase NGOK (2007), p. 155.

81 NGOK (2007), pp. 155 y s.

82 Ibíd., pp. 155-157.

83 Entre otros, sir David Akers-Jones, el ex Secretario Jefe de Hong Kong en la era colonial, era conocido como promotor de reestructurar la legislatura como un sistema bicameral.
} 
del poder atribuido a la cámara legislativa alta determinaría el contenido democrático de la nueva estructura. Wesley-Smith ha afirmado enfáticamente: "Una cámara alta no elegida democráticamente (e.g. la Cámara de los Lores en el Reino Unido) podría aún ser aceptable, aunque sea marginalmente, si únicamente pudiera invalidar y no rechazar legislación" 84 . Young, por su parte, ha ofrecido una propuesta novedosa y creativa de transformar las circunscripciones funcionales en algo compatible con el sufragio universal ${ }^{85}$.

Es altamente probable que las circunscripciones funcionales permanezcan como una institución política clave en una forma u otra en el futuro, incluso si las elecciones del Consejo Legislativo son democratizadas. Es tiempo de considerar cuidadosamente las propuestas de transformación de las circunscripciones funcionales en un mecanismo que satisfaga estándares democráticos. Es igualmente importante considerar las medidas interinas de reforma de las circunscripciones funcionales entre ahora y la eventual reforma electoral del Consejo Legislativo ${ }^{86}$.

\subsection{El dilema de la nominación: elección del} Jefe Ejecutivo por sufragio universal

Un clásico escenario de crisis constitucional en una futura elección directa del Jefe Ejecutivo sería aquel en que el pueblo de Hong Kong elija a una figura política inaceptable para Beijing y el Gobierno Central rehúse ejercer su poder de nominación ${ }^{87}$. ¿Hay alguna forma de prevenir que esto ocurra? Académicos chino-continentales ponen mucho énfasis en la composición del futuro Comité Nominador y en la importancia de concesiones políticas tales como que ningún nominado sea inaceptable para Beijing. Desde la perspectiva jurídica china continental, esto concuerda con el principio de una "participación equilibrada" y el requerimiento de "patriotismo", el cual aun no siendo estrictamente un requerimiento jurídico, se mantiene como un referente político importante para nombramientos gubernamentales relevantes. La posición liberal afirma que esto inevitablemente introduciría una prueba de fuego

\footnotetext{
84 Wesley-Smith (2005), p. 68.

85 Young (2005), pp. 53-58.

86 Los demócratas sugirieron medidas interinas para mejorar el contenido democrático del sistema electoral de Hong Kong tales como la abolición de los votos corporativos y la extensión del sufragio en las circunscripciones funcionales. Tales medidas pueden ser implementadas sin necesidad de la aprobación de Beijing.

87 Desde la perspectiva jurídica china, el poder del Gobierno Popular Central para designar al Jefe Ejecutivo es un poder sustantivo conforme al artículo 45(1) de la Ley Básica.
} 
de lealtad a Beijing para que cualquiera sea elegible para la elección general de Jefe Ejecutivo. Este sistema no sólo bloquearía potenciales candidatos que sostuvieran posiciones disidentes sino que también excluiría a políticos con una fuerte agenda basada en clases sociales. Por ejemplo, un líder sindical, sin importar cuán popular sea entre el público general, podría no recibir apoyo en el Comité Nominador si se permite al sector empresarial un veto efectivo sobre el proceso de nominación. Un umbral irracionalmente alto de nominación tiene el indeseable efecto de excluir a una gran porción de candidatos por lo demás altamente calificados de competir por el cargo superior en la región. La cuestión es, entonces, si es posible alcanzar alguna solución intermedia que promueva la máxima participación con filtros políticos mínimos, por un lado, y que prevenga el estancamiento político en la forma de crisis constitucional, por el otro 88 .

\section{LA EVOLUCIÓN DE LAS CONVENCIONES CONSTITUCIONALES: ¿POR QUÉ LA IMPLEMENTACIÓN DEL SUFRAGIO UNIVERSAL ES IMPORTANTE?}

Las convenciones constitucionales llenan vacíos en el texto constitucional, fijando usos políticos generalmente observados por los órganos del Estado. Ellas establecen precedentes de práctica y sientan las bases de los procedimientos constitucionales en áreas no cubiertas por la constitución escrita. La posición liberal sostiene que el "activismo político ad hoc" 89 de Beijing y la falta de predictibilidad en el ejercicio de la discreción soberana, evidenciada en interpretaciones previas del Comité Permanente ${ }^{90}$ han estado erosionando la autonomía de Hong Kong. Suponiendo que la implementación del sufragio universal tenga el efecto de institucionalizar la resistencia de la Coalición de Oposición a las acciones unilaterales de Beijing, el riesgo de crisis constitucional sería aún mayor que ahora, si la voluntad del soberano colisionara con la resistencia institucionalizada de Hong Kong. Se sostiene que las convenciones constitucionales serían efectivas en la resolución de esta posible confrontación. Resulta interesante anotar que la discusión académica sobre la evolución de las convenciones constitucionales en

88 Por ejemplo, véanse los cuatro principios para la nominación del Jefe Ejecutivo para 2017 propuestos por Sing; Cummings (2010), p. 53.

89 Xingzhong (2007), p. 183.

90 GHai (2004). 
Hong Kong sea escasa. Hay ocasional desarrollo del concepto, pero sin discusión en profundidad sobre los detalles operativos ${ }^{91}$.

Comentando el tópico de la interpretación de la Ley Básica, Chen ha señalado:

"A diferencia de la compleja jurisprudencia que domina la división de poder entre las autoridades nacionales y provinciales en sistemas federales, la jurisprudencia acerca 'un país, dos sistemas' es relativamente simple. El Comité Permanente posee autoridad suprema sobre la interpretación de la Ley Básica -incluyendo las disposiciones de la Ley Básica relativas a asuntos domésticos de Hong Kong- la puede ejercer a través del proceso legislativo de interpretación. Si es que, cuándo y cómo ejercerá este poder no está regido por ley, sino que es una cuestión de práctica que es, o con suerte será, regida por convenciones constitucionales evolutivas que suplementen el texto escrito de la Ley Básica”92.

Sugerir el uso de las convenciones para la regulación de interacciones constitucionales no significa que simplemente se deba aplicar convenciones continentales o del common law, sin mayor consideración. En efecto, la controversia en la determinación del mandato restante del Jefe Ejecutivo posterior a la renuncia de Tung Chee Hwa's - primer Jefe Ejecutivo de Hong Kong- indica que Hong Kong necesita un elaborado régimen de convenciones que sea suficientemente maduro para abordar estas intrincadas tensiones constitucionales ${ }^{93}$.

Las convenciones constitucionales requieren tiempo para evolucionar. Gran Bretaña, que carece de constitución escrita, confía profundamente en las convenciones constitucionales. Le tomó cientos de años a Gran Bretaña llegar a donde está ahora. La literatura sobre la teoría jurídica tras las convenciones constitucionales necesita ser estudiada cuidadosamente. Por ejemplo, Jennings ha observado que la creación de una convención depende de (i) cuales fueran los precedentes; (ii) si los actores en los precedentes creían estar vinculados por una regla, y (iii) si había una razón para la regla ${ }^{94}$. Barber, a su vez, discute la posibilidad de una consolidación de las convenciones constitucionales por la vía de las decisiones judiciales -i. e. el ejercicio de los poderes de creación de derecho por el Tribunal, deviniendo así una convención en jurisprudencia-o por la vía de

\footnotetext{
91 Lo (2003), pp. 84-94.

92 Chen (2006), p. 651.

93 Para una crítica sobre este punto, véase TAI (2005), pp. 9 y ss.

94 Jennings (1959), p. 136.
} 
la progresión empleando un enfoque jurídico positivista ${ }^{95}$. Para el segundo tipo de consolidación, Barber nota que la teoría de Hart sobre la formalización de las convenciones en un sistema jurídico mediante una progresión gradual podría ser aplicada en el contexto constitucional ${ }^{96}$. En el contexto de la Ley Básica, las convenciones constitucionales futuras podrían transformarse en normas jurídicas con el tiempo. En casos extremos, una convención con gran fuerza normativa podría llegar a consolidarse como una enmienda a la Ley Básica. El Tribunal de Última Instancia también podría representar un rol en el afianzamiento de convenciones constitucionales desarrolladas con el tiempo.

La posición liberal ha criticado vehementemente las interpretaciones del Comité Permanente como transgresiones a los límites dentro de los cuales un soberano con compromisos solemnes a la autonomía de la región tiene permitido operar. Sin embargo, desde el punto de vista de Beijing, la inmadurez del régimen de la Ley Básica crea nuevos problemas que requieren interpretaciones de autoridad y decisiones cruciales del órgano estatal supremo que confirió poderes a Hong Kong. La evolución de las convenciones constitucionales y, cuando sea necesario, subsiguientes afianzamientos de las convenciones darían a la Ley Básica un carácter dinámico, uno que se reforme a sí mismo con el tiempo y al hacerlo dé debida consideración a las preocupaciones políticas y doctrina de ambos lados de la costa. Las convenciones constitucionales son particularmente importantes para el desarrollo del sufragio universal en Hong Kong.

El desarrollo de la convención es también altamente relevante en la optimización de la función del Comité para la Ley Básica como interfaz constitucional entre Beijing y Hong Kong, según se explorará en la siguiente sección.

\section{El rol del Comité para la Ley Básica: una indispensable interfaz y la CABEZA DE PUENTE PARA EL RAZONAMIENTO JURÍDICO}

El Comité para la Ley Básica es un órgano consultivo del Comité Permanente sobre cuestiones que involucraran la interpretación de la Ley Básica. Así, el último debe consultar al primero antes de tomar cualquier determinación bajo los artículos 17 (invalidar la legislación de Hong Kong que resulte contraria a la Ley Básica), 18 (determinar las leyes nacionales aplicables en Hong Kong), 158 (interpretar la Ley Básica) y 159 (proponer reformas a la Ley Básica) de la

95 BARber (2009), pp. 301-304.

96 Ibíd., p. 304. 
Ley Básica. Por un lado, algunos académicos han explorado la posibilidad de transformar al Comité para la Ley Básica en una corte cuasiconstitucional, en materias que requieran el ejercicio de las competencias interpretativas del Comité Permanente ${ }^{97}$. Pero se expresa reserva sobre esta posibilidad, dada la falta de oportunidad para desarrollar jurisprudencia bajo el artículo 158 de la Ley Básica. Por el otro lado, algunos académicos son generalmente pesimistas acerca de la posibilidad de que el Comité para la Ley Básica desempeñe cualquier rol clave en el proceso constitucional en absoluto ${ }^{98}$.

El Comité para la Ley Básica es un cuerpo importante en el marco constitucional existente ${ }^{99}$. Incluso se podría argumentar que éste sería aún más instrumental antes que después de la implementación del sufragio universal por las siguientes razones:

a) Cuando tanto el poder ejecutivo y legislativo son manejados por el proceso democrático, cualquier decisión hecha por el gobierno o por el Comité Legislativo acarrea con sí gran peso político y legitimidad. Sería muy difícil, o al menos conllevaría un costo político sustancial, para Beijing intentar modificar o invalidar tal decisión simplemente por una acción política unilateral, aun si fuera discutible que la decisión era concerniente a un asunto que caía fuera de la autonomía de Hong Kong. Probablemente podría disipar un estancamiento político, proveyendo un foro relativamente independiente para arbitrar asuntos constitucionales sobre la base del razonamiento jurídico o al menos conducido en un procedimiento menos políticamente teñido. También podría asistir al Comité Permanente en el desarrollo de un método de interpretación por principios ${ }^{100}$.

b) Ejerciendo sus poderes asesores, podría actuar no sólo como mediador de disputas constitucionales respecto de asuntos en los que la Ley Básica requiera que el Comité Permanente le consulte. Por convención, éste también podría actuar de iniciativa propia como un "regulador" informal de procedimientos constitucionales. De todas las entidades regidas por el marco constitucional de Hong Kong, el Comité para la Ley Básica está en la mejor posición para otorgar consejo constructivo al Comité Permanente sobre la legalidad del proceso constitucional. Por supuesto, este órgano no tiene poderes sustantivos y sus recomendaciones son,

\footnotetext{
97 TAI (1999), p. 90.

98 Ghai (2007), p. 400.

99 Ghai (1999), p. 197.

100 GHaI (2007), p. 400.
} 
cuando mucho, persuasivas. Con todo, tener un regulador informal que ejerce alguna fuerza normativa sobre los procedimientos constitucionales es mejor que no tener ninguno. Naturalmente, si el Comité para la Ley Básica debería adoptar semejante rol activo es controversial ya que actualmente este órgano actúa más bien como un consejero pasivo que sólo da recomendaciones al ser consultado por el Comité Permanente.

Una prevención es necesaria para evitar que el Comité para la Ley Básica exceda su competencia asignada, para tratar con asuntos políticos más amplios. Una extensión de su ámbito de acción a estos asuntos probablemente politizaría su labor, desviando su atención sobre la validez del proceso constitucional ${ }^{101}$. A pesar del potencial del Comité Permanente en los años venideros en la optimización de su influencia en el proceso constitucional, hay una serie de debilidades inherentes que, de no ser abordadas apropiadamente, podrían limitar las funciones del Comité para la Ley Básica. Ni la Ley Básica ni la decisión del Comité Permanente de establecer el Comité para la Ley Básica proveen indicación clara respecto de cómo éste ejercerá sus funciones asesoras ${ }^{102}$. Dado que su consejo no es publicado, no hay claridad sobre el exacto alcance que su influencia ha tenido en las determinaciones del Comité Permanente. Una serie de mejoras probablemente harían las funciones y operaciones del Comité para la Ley Básica más efectivas y coherentes:

a) Vale la pena considerar si la integración del Comité para la Ley Básica debiera ser expandida para incluir a más expertos en derecho constitucional.

b) El requerimiento de consulta del Comité para la Ley Básica al Comité Permanente en la adopción de determinaciones importantes es fútil a menos que haya alguna forma de convención conforme a la cual el consejo de aquél deba ser seguido generalmente por éste.

c) Dado el importante rol constitucional del Comité para la Ley Básica, su labor requiere mayor transparencia. Debería considerarse que en futuras interpretaciones del Comité Permanente, en las que el Comité para la Ley Básica haya sido consultado, se publique un resumen de su consejo. Dicho consejo debería versar sobre la licitud del asunto constitucional y no sobre política. Asimismo,

101 GHAI (1999), p. 197.

102 La decisión del Comité Permanente que configura el Comité para la Ley Básica dispone que la función de éste es "estudiar preguntas" surgidas de la implementación de los artículos relevantes, mientras que la Ley Básica simplemente dice que el Comité Permanente debe consultar al Comité para la Ley Básica antes de dar su propia decisión o interpretación. Ibíd., pp. 196 y ss. 
su razonamiento jurídico debería ser expuesto claramente, en forma similar al pronunciamiento de una corte ${ }^{103}$.

d) Podría considerarse que el Comité para la Ley Básica pueda ofrecer de oficio consejo al Comité Permanente sobre asuntos constitucionales vitales en los que haya una clara divergencia entre la percepción jurídica china y la doctrina del common law. Otra posible ruta es establecer una convención según la cual el Comité Permanente pudiera consultar regularmente al Comité para la Ley Básica, no simplemente restringida a los asuntos que requieren consulta de acuerdo con la Ley Básica. De este modo, cualquier posible controversia se encontraría bajo el radar de éste antes de que el asunto estalle en otra crisis constitucional.

\section{Conclusión}

1. La instauración del sufragio universal representa un elemento clave en la auténtica consecución del "elevado grado de autonomía” que la Ley Básica atribuye a Hong Kong y en el genuino éxito de la fórmula "un país, dos sistemas". De momento, sin embargo, el proceso de democratización en Hong Kong se encuentra estancado. Así lo demuestran la Decisión del Comité Permanente del 31 de agosto de 2014 en orden a imponer requisitos restrictivos para la implementación del sufragio universal y el rechazo del Consejo Legislativo al paquete de reformas propuestas por el Jefe Ejecutivo. Pese al masivo descontento popular expresado en la Revolución de los Paraguas, a la fecha no hay indicación de que Beijing esté dispuesto o preparado para cambiar de posición en relación a este punto. Es así como la búsqueda de la democracia en Hong Kong parece haber fracasado.

2. En la literatura sobre el particular el debate sobre la instauración del sufragio universal suele ser analizado sobre la base de consideraciones de Realpolitik y de economía política. Sin desconocer la importancia y utilidad de tales consideraciones para comprender las posiciones de Beijing y de Hong Kong sobre el particular, esta investigación ha propuesto una perspectiva de análisis diverso. Aquí se ha sostenido que la divergencia de tradiciones jurídicas involucradas resulta igualmente importante para la comprensión del conflicto. Justamente, a la luz de esta divergencia puede explicarse en las discrepancias entre las concepciones de Beijing y de Hong Kong respecto de la configuración institucional del sufragio universal y de la internacionalización del derecho constitucional.

103 GHaI (2001), pp. 14 y ss. 
3. En síntesis, la posición del Gobierno Central sobre el sufragio universal es que la reforma electoral de Hong Kong debe ser realizada conforme a la Ley Básica, así como con la interpretación legítima y las decisiones del Comité Permanente, y no conforme al artículo 25(b) del PIDCP. Esta posición demuestra la preferencia china por el método positivista, así como la tendencia a confiar en las leyes y normas domésticas al tratar con asuntos constitucionales. Desde la perspectiva doctrinaria china, toda interpretación o decisión del Comité Permanente tiene rango legal. En consecuencia, la Decisión del 31 de agosto constituye por tanto un marco vinculante y cualquier propuesta futura para cambiar el sistema electoral debe conformarse a ella, de modo que un eventual intento político por ir más allá de su alcance, con seguridad tendrá severas repercusiones.

4. Por otro lado, una de las principales inquietudes desde la perspectiva liberal es que se introduzcan reformas al sistema electoral en el nombre de la democratización, pero que de hecho ubiquen a la Coalición de Oposición en una posición de desventaja. Un umbral aceptable de nominación en la elección de Jefe Ejecutivo -en lugar de una diseñada para eliminar al candidato de oposición- y la abolición de las circunscripciones funcionales en las elecciones del Consejo Legislativo se han convertido en los pilares cardinales de la perspectiva liberal en el aseguramiento de lo que ella considera ser verdaderamente el sufragio universal. Aunque hay desacuerdos en la Coalición de Oposición sobre el método para lograr una plena democratización, existe consenso respecto de que el marco normativo que debe guiar el proceso está dado por el artículo 25(b) del PIDCP y por el artículo 21(b) de la OCD.

5. Con todo, todavía queda algo de flexibilidad dentro del marco institucional y procedimental establecido por Beijing para la reforma electoral. Por ejemplo, algunas propuestas apuntan a la transformación de las circunscripciones funcionales, de manera que la estructura legislativa de Hong Kong transite desde el unicameralismo al bicameralismo. De igual modo, se plantea que las convenciones constitucionales pueden contribuir a alcanzar un punto de equilibrio entre la aspiración la máxima participación de los ciudadanos, con la preocupación por la posibilidad de que Hong Kong se transforme en una base anti-Beijing. Finalmente, otra alternativa es dar una relectura al rol del Comité para la Ley Básica, de manera tal que sus competencias se orienten a la mediación y a la regulación informal de procedimientos constitucionales, por la vía de la emisión de recomendaciones al Comité Permanente.

6. En este sentido, el desarrollo de la democracia en Hong Kong requiere dos elementos vitales, cuya importancia ha sido pasada por alto en el pasado. 
El primero es la creatividad en el desarrollo de soluciones constitucionales aceptables para ambos bandos (por ejemplo, empleando el silencio en los textos constitucionales vigentes). El segundo es la disposición para involucrarse en un dialogo de buena fe con el pueblo de Hong Kong sin comprometer los valores e intereses fundamentales de cada lado. Propuestas creativas y diálogo constructivo son imposibles sin una profunda comprensión acerca de la doctrina constitucional de ambas partes. Igualmente importante es la disposición para afianzar la interfaz institucional necesaria para promover la convergencia de normas. De ahí la importancia de estudiar el conflicto constitucional de Hong Kong desde la perspectiva de la doctrina constitucional comparada, y no sólo bajo los lentes de la economía política.

\section{Bibliografía CiTADA}

BARber, Nicholas W. (2009). "Laws and Constitutional Conventions". Law Quarterly Review. Volumen 125, pp. 294-309.

Byrnes, Andrew (1999). "And Some Have Bills of Rights Thrust Upon Them: The Experience of Hong Kong's Bill of Rights", en Philip Alston (ed.), Promoting Human Rights Through Bills of Right: Comparative Perspectives. Oxford, Oxford University Press, pp. 318-391.

CHAn SC, Johannes (2007). "Basic Law and Constitutional Review: The First Decade", en Hong Kong Law Journal. Volumen 37 (№ 2), pp. 407-448.

Chang, Denis (2007). "The Imperatives of One Country, Two Systems: One Country before Two Systems?”, en Hong Kong Law Journal. Volumen 37 (No 2), pp. 351-362.

Chen, Albert H.Y. (2009). "International Human Rights Law and Domestic Constitutional Law: Internationalisation of Constitutional Law in Hong Kong”, en National Taiwan University Law Review. Volumen 4, pp. 237-333.

Chen, Albert H.Y. (2006). "Constitutional Adjudication in Post-1997 Hong Kong”. Pacific Rim Law \& Policy Journal. Volumen 15, No 3, pp. 627-682.

Chen, Albert H.Y. (2002). "Hong Kong's Legal System in the New Constitutional Order: The Experience of 1997-2000", en Jianfu Chen, Yuwen Li y Jan Michiel Otto. Implementation of Law in the People's Republic of China (La Haya, Boston, Kluwer Law International), pp. 213-245.

Chu, Yin-wah; So, Alvin (2013). "Can Hong Kong Design a New Growth Engine? A Study of the Absence of Economic Policies of the Donald Tsang Regime", En: Joseph Y.S. Cheng (ed). The Second Chief Executive of Hong Kong SAR: Evaluating 
the Tsang Years 2005-2012 (Hong Kong, City University of Hong Kong Press), pp. 122-227.

DAVIS, Michael C. (2007). "Interpreting Constitutionalism and Democratization in Hong Kong”. En: Hualing Fu, Lison Harris y Simon N.M. Young (eds.). Interpreting Hong Kong's Basic Law: The Struggle for Coherence. New York, Palgrave Macmillan, pp. 77-95.

Delisle, Jacques; Lane, Kevin P. (2004). "Hong Kong's Endgame and The Rule of Law (I). The Struggle Over Institutions and Values in the Transition To Chinese Rule". Pennsylvania Journal of International Economic Law. Volumen 25, pp. 1467-1523.

FEnG, Lin (2001). "The Development of Jurisprudence of the Court of Final Appeal in Basic Law Litigation". Journal of Chinese and Comparative Law. Volumen 5, pp. 21-44.

Geping, Rao (饶戈平) (2008). "Ren Quan Gong Yue Bu Gou Cheng Xiang Gang Pu Xuan De Fa Lu Gen Ju (人权公约不构成香港普选的法律根据) [Trad: El PIDCP no es la base legal para el sufragio universal de Hong Kong], en Peking University Law Journal (中外法) (No 3), pp. 448-456.

GHAI, Yash (2007). "The Intersection of Chinese Law and the Common Law in the Hong Kong Special Administrative Region: Question of Technique or Politics?", en Hong Kong Law Journal. Volumen 37 (No 2), pp. 363-406.

GHAI, Yash (2004). "Interpreting the Basic Law is not what it seems", en Apple Daily, [fecha de consulta: 23 de diciembre de 2017]. [Disponible en: http:// www.hkhrm.org.hk/CR/ghai_0426.html].

GHAI, Yash (2001). "Resolution of Disputes between the Central and Regional Governments: Models in Autonomous Regions", en Journal of Chinese and Comparative Law. Volumen 5, pp. 1-22.

GHAI, Yash (1999). Hong Kong's New Constitutional Order: The Resumption of Chinese Sovereignty and the Basic Law (Hong Kong, Hong Kong University Press).

GHaI, Yash (1993). "Derogations and Limitations in the Hong Kong Bill of Rights". En Johannes Chan y Yash Ghai (eds.). The Hong Kong Bill of Rights: A Comparative Approach (Hong Kong, Butterworths Asia), pp. 161-200.

Jennings, Ivor (1959). The Law and the Constitution (Londres, University of London Press).

Leung, Priscilla (2000). "The Applicability of National Laws in Hong Kong”, en Hong Kong Lawyer, pp. 26-28. 
LI, Gladys; Kat, Nigel (2006). "The legal status of functional constituencies". En: Christine Loh; Civic Exchange (eds.). Functional Constituencies: A Unique Feature of the Hong Kong Legislative Council (Hong Kong, Hong Kong University Press), pp. 143-154.

Lin, Laifan; Gu, Minkang (2001-2002). "Interpretation of the Basic Law: Viewpoints from a Pure Jurisprudence", en Journal of Chinese and Comparative Law. Volumen 5 (No 1), pp. 73-92.

Lo, Sonny (2003). Constitutional Conventions and Political Reform. En: Christine Loh y Civic Exchange, (ed.). Building Democracy: Creating Good Government for Hong Kong (Hong Kong, Hong Kong University Press), pp. 84-94.

NgoK, Ma (2007). Political Development in Hong Kong: State, Political Society, and Civil Society (Hong Kong, Hong Kong University Press).

SHuwen, Wang (王叔文) (2006). Xianggang Tebie Xingzhengqu ji ben fa dao lun (香港特别行政区基本法导论) [Trad: Introducción a la Ley Básica de la Región Administrativa Especial de Hong Kong] (Beijing, Zhongguo Minzhu Fazhi Chuban She) [中国民主法制出版社].

Siming, Fu (傅思明) (1997). Xianggang Tebie Xingzhengqu ji ben fa tong lun ( 香港特别行政区基本法通论) [Trad: Ley Básica de la Región Administrativa Especial de Hong Kong] (Beijing, China Procuratorate Press) (中国检察出版社).

Sing, Ming y Cummings, Lucy (2010). Constitutional Reform for Good Governance in Hong Kong Special Administrative Region (Hong Kong, Centre for Comparative and Public Law).

TAI, Benny Y. T. (2005). "A Tale of the Unexpected: Tung's Resignation and the Ensuing Constitutional Controversy", en Hong Kong Law Journal, Volumen 35 (No 1), pp. 7-16.

TAI, Benny Y. T. (2002). "The Principle of Minimum Legislation for Implementing Article 23 of the Basic Law", en Hong Kong Law Journal, Volumen 32 (No 3), pp. 579-614.

TAI, Benny Y. T. (1999). “The Development of Constitutionalism in Hong Kong”. En: R. Wacks (ed.). The New Legal Order in Hong Kong (Hong Kong, Hong Kong University Press), pp. 39-93.

Walker, Neil (2008). “Taking Constitutionalism Beyond the State”, en Political Studies, Volumen 25, pp. 519-543.

WANG, Zhenmin (2007). "From the Judicial Committee of the British Privy Council to the Standing Committee of the Chinese National People's Con- 
gress - an Evaluation of the Legal Interpretive System after the Handover", en Hong Kong Law Journal. Volumen 37 (No 2), pp. 605-618.

Wang, Guiguo; Leung, Priscilla M.F. (1998). "One Country, Two Systems: Theory Into Practice", Pacific Rim Law \& Policy Journal. Volumen 7 (No 2), pp. 279-321.

Wesley-Smith, Peter (2005). "Bicameralism and its Relevance for the Hong Kong Legislature". En: Johannes Chan y Lison Harris (eds.). Hong Kong's Constitutional Debates (Hong Kong, Hong Kong Law Journal Limited), pp. 67-72. XIngzhong, Yu (2007). "Formalism and Commitment in Hong Kong's Constitutional Development". En: Hualing Fu, Lison Harris, Simon N.M. Young (eds.). Interpreting Hong Kong's Basic Law: The Struggle for Coherence (New York, Palgrave Macmillan), pp. 183-197.

Yeung, Chris (2002). "Separation and Integration: Hong Kong-Mainland Relations in a Flux", en Lau Siu-kai (ed.). The First Tung Chee-hwa Administration: The First Five Years of the Hong Kong Special Administrative Region. Hong Kong, Chinese University Press, pp. 237-265.

Young, Simon N. M. (2014). "Realising Universal Suffrage in Hong Kong after the Standing Committee's Decision”, en Hong Kong Law Journal. Volumen 44 (No 3), pp. 689-708.

Young, Simon N. M. (2006). "Elected by the elite: Functional constituency legislators and elections", en Christine Loh; Civic Exchange (eds.). Functional Constituencies: A Unique Feature of the Hong Kong Legislative Council, (Hong Kong, Hong Kong University Press), pp. 111-142.

Young, Simon N. M. (2005). "Can Functional Constituencies Co-exist with Universal Suffrage?”, en Johannes Chan y Lison Harris, Hong Kong's Constitutional Debates (Hong Kong, Hong Kong Law Journal Limited), pp. 53-58.

Young, Simon N. M. (2004). "Restricting Basic Law Rights in Hong Kong", en Hong Kong Law Journal, Volumen 34 (No 1), pp. 109-132.

Young, Simon N. M. (1997). "The Meaning of the Right To Vote In Hong Kong”, McGill Law Journal, Volumen 42, pp. 649-729.

Young, Simon N.M.y LaW, Anthony (2006). "Inequalities and anomalies of the FC system", en Christine Loh; Civic Exchange (eds.), Functional Constituencies: A Unique Feature of the Hong Kong Legislative Council (Hong Kong, Hong Kong University Press), pp. 59-109. 
Zhe, Zhu (2007). "HK Basic Law 'guarantees democracy", China Daily, 7 de junio de 2007, [fecha de consulta: 23 de diciembre de 2017]. [Disponible en: http://www.chinadaily.com.cn/china/2007-06/07/content_888810.htm].

ZHu, Guobin (2006). Zhongguo Xianfa yu Zhengzhi Zhidu (中国宪法与政治制度) [Sistema de derecho constitucional y político chino] (Beijing, Law Press China) (法律出版社).

\section{JURISPRUDENCIA CITADA}

\section{Del Tribunal de última instancia}

Chan Kin Sum v. Secretary for Justice [2009] 2 HKLRD 166.

Chan Yu Nam v. Secretary for Justice HCAL 32 y 55/2009.

Chan Wah v. Hang Hau Rural Committee [2000] 1 HKLRD 411.

HKSAR v. Ng Kung Siu [1999] 3 HKLRD 907.

Secretary for Justice v. Chan Wah [2000] 3 HKLRD 641.

Lau Kong Yung v. the Director of Immigration[1999] 3 HKLRD 778.

\section{Del Tribunal de Apelaciones}

Attorney-General of Hong Kong v. Lee Kwong Kut [1993] AC 951.

R. v. Sin Yau-ming (1991) 1 HKPLR 88.

\section{Del Tribunal Superior}

Lee Miu Ling v. Attorney General (1995) 5 HKPLR 181.

\section{NORMAS JURÍDICAS CITADAS}

Ley Básica de la Región Administrativa Especial de Hong Kong de la República Popular China, [fecha de consulta: 13 de diciembre de 2017]. [Version oficial en inglés disponible en: http://www.basiclaw.gov.hk/en/basiclawtext/images/ basiclaw_full_text_en.pdf].

Ordenanza para la elección del Jefe Ejecutivo. [fecha de consulta: 21 de diciembre de 2017]. [Versión oficial en inglés disponible en: http://www.blis.gov.hk/ blis_pdf.nsf/6799165D2FEE3FA94825755E0033E532/0B621C1E1F7C5 B7A482575EF001BF072/\$FILE/CAP_569_e_b5.pdf]. 
Ordenanza sobre el Consejo Legislativo, [fecha de consulta: 23 de diciembre de 2017]. [Versión oficial en inglés disponible en: http://www.hklii.org/eng/ hk/legis/ord/542/].

Ordenanza sobre la Carta de Derechos, [fecha de consulta: 23 de diciembre de 2017]. [Versión oficial en inglés disponible en: http://www.hab.gov.hk/file_ manager/en/documents/references/papers_reports_others/human_rights/ CAT2_Annex2_e.pdf].

\section{OTROS DOCUMENTOS OFICIALES CITADOS}

Decision of the Standing Committee of the National People's Congress on Issues Relating to the Methods for Selecting the Chief Executive of the Hong Kong Special Administrative Region and for Forming the Legislative Council of the Hong Kong Special Administrative Region in the Year 2012 and on Issues Relating to Universal Suffrage [fecha de consulta: 1 de julio de 2017]. [Disponible en:http://www.cmab.gov.hk/cd/eng/basic/pdf/decision.pdf].

Decision of the Standing Committee of the National People's Congress on Issues Relating to the Selection of the Chief Executive of the Hong Kong Special Administrative Region by Universal Suffrage and on the Method for Forming the Legislative Council of the Hong Kong Special Administrative Region in the Year 2016, [fecha de consulta: 12 de julio de 2017]. [Disponible en: http://www.2017.gov.hk/filemanager/template/en/doc/20140831b.pdf].

Decision of the Standing Committee of the National People's Congress on Issues Relating to the Methods for Selecting the Chief Executive of the Hong Kong Special Administrative Region in the Year 2007 and for Forming the Legislative Council of the Hong Kong Special Administrative Region in the Year 2008, [fecha de consulta: 12 de julio de 2017]. [http://www.npc.gov. cn/englishnpc/Law/2007-12/12/content_1383886.htm].

Method for Selecting the Chief Executive by Universal Suffrage: Consultation Report and Proposals. [fecha de consulta: 23 de diciembre de 2017]. [Disponible en: http://www.2017.gov.hk/filemanager/template/en/doc/report_2nd/ consultation_report_2nd.pdf].

Motion concerning the Amendment to the Method for the Selection of the Chief Executive of the Hong Kong Special Administrative Region, [fecha de consulta: 23 de diciembre de 2017]. [Disponible en: http://www.legco. gov.hk/yr14-15/english/hc/papers/hc20150605cb3-727-e.pdf]. 
Motion concerning the Amendment to the Method for the Selection of the Chief Executive of the Hong Kong Special Administrative Region [fecha de consulta: 23 de diciembre de 2017]. [Disponible en: http://www.legco.gov. hk/yr14-15/english/hc/papers/hc20150605cb3-727-e.pdf].

Report on the Public Consultation on the Methods for Selecting the Chief Executive in 2017 and for Forming the Legislative Council in 2016, [fecha de consulta: 12 de julio de 2017]. [Disponible en: http://www.2017.gov.hk/ filemanager/template/en/doc/report/consultation_report.pdf].

The Interpretation by the Standing. Committee of the National People's Congress of Article 7 of Annex I and Article III of Annex II to the Basic Law of the Hong Kong Special. Administrative Region of the People's Republic of China, [fecha de consulta: 20 de noviembre de 2017]. [Disponible en http:// www.blis.gov.hk/blis_ind.nsf/CurAllEngDoc/E6EBECD7F638441748257 5EE000E1080?OpenDocument].

2011 Election Committee Subsector Elections Breakdown of Voters for Election Committee Subsectors, [fecha de consulta: 23 de diciembre de 2017]. [Disponible en: http://www.eac.gov.hk/pdf/chief/en/2012_CE_Report/2012ce_appendix_II.pdf].

2016 Election Committee Subsector Elections Breakdown of Voters for Election Committee Subsectors, [fecha de consulta: 23 de diciembre de 2006]. [Disponible en: http://www.eac.gov.hk/pdf/chief/en/2017_CE_Report/2017ce_appendix_II.pdf]. 
